\title{
Adiabatic decohesion in a thermoplastic craze thickening at constant or increasing rate
}

\author{
Patrick S. Leevers, Marie-Aude Godart \\ Department of Mechanical Engineering, Imperial College London, \\ London SW7 2AZ, UK
}

\begin{abstract}
When a crack in a thermally non-diffusive material is impact loaded - or propagates at high speed - a cohesive process which resists slow crack extension may itself cause decohesion by adiabatic heating. By assuming that decohesion ultimately occurs by low-energy disentanglement within a melt layer of critical thickness, the fracture resistance of craze-forming crystalline polymers can be estimated quantitatively. Previous estimates used a simple, thermomechanically linear representation of craze fibril drawing. This paper presents a more physically realistic, numerical formulation, and demonstrates it for constant craze thickening rate (as imposed by an ideal full-notch tension test) and for linearly increasing thickening rate (as at the tip of an impact-loaded or rapidly propagating crack). For a linear material, the numerical formulation gives results which asymptotically approach those from analytical solutions, as craze density approaches zero. In more realistic model polymers, the enthalpy of fusion increasingly delays decohesion as impact speed increases, although the temperature distribution of an endotherm appears to have little effect. Increasing molecular weight, heuristically associated with decreasing craze density and increasing structural dimension, increases the predicted impact fracture resistance. In every case, fracture resistance passes through a minimum as impact speed increases. The conclusions encourage the use of impact fracture tests, and discourage the use of the full-notch tension test, to assess the dynamic fracture resistance of a craze-forming polymer.
\end{abstract}

Key words: Crack propagation and arrest, dynamic fracture, fracture mechanisms, fracture toughness, polymeric material

\section{Nomenclature}

$\beta$ Thermomechanical efficiency

$\Delta H$ Enthalpy

Preprint submitted to Elsevier

31 August 2008 
$\Delta H_{\mathrm{f}}$ Latent heat of fusion

$\dot{q}^{\prime \prime}$ Planar thermomechanical heat source at active layer

$\eta, \dot{\eta}$ Local thickness, opening rate of cohesive zone

$\Gamma_{\mathrm{V}}$ Dimensionless crack driving force

$\kappa$ Bulk thermal diffusivity

$\lambda_{\mathrm{D}}, \lambda_{\mathrm{F}}$ Natural draw ratio, fibril draw ratio

$\rho$ * Relative density of craze

$\rho$ Mass density

$\sigma_{\mathrm{c}}$ Cohesive stress

$F o ; F_{\mathrm{dc}}$ Fourier number; Fourier number at decohesion

$\xi$ Distance from craze tip to crack tip

$a, \dot{a}$ Crack length, velocity

$B$ Specimen thickness

$B_{\mathrm{C}}$ Crack path width

$c$ Crack-tip craze length

$C, C^{*}$ Absolute, normalised load-point compliance of specimen

$C_{\mathrm{p}}$ Specific heat

$E^{\prime}$ Reduced tensile modulus

$G$ Crack driving force

$G_{\mathrm{C}}$ Fracture initiation resistance

$G_{\mathrm{D}}$ Dynamic fracture (rapid crack propagation) resistance

$h$ Craze fibril surface heat transfer coefficient

$j$ Finite volume cell number

$k$ Bulk thermal conductivity

$L_{0}$ Initial finite volume cell size

$M, M_{\text {eff }}$ Monodisperse, effective polydisperse molecular mass

$N_{\mathrm{F}}$ Number of craze fibrils per unit craze area

$N_{\mathrm{a}}$ Number of active Lauterwasser-Kramer craze surfaces

$N_{\mathrm{Z}}$ Number of heat transfer directions $\left(1 \leq N_{\mathrm{Z}} \leq 2\right)$

$q$ Heat exchange

$s_{\mathrm{C}}$ Critical structural dimension of material

$T$ Temperature

$T_{0}$ Initial bulk temperature

$t_{\mathrm{dc}}, t_{\mathrm{dc} 0}$ Decohesion time, decohesion time for zero-density craze

$T_{\mathrm{m}}$ Melting temperature

$v, \dot{v}$ load point displacement, displacement rate

$V_{\text {c }}$ Applied constant craze opening rate

$W$ Crack path length of specimen geometry

$z$ Coordinate normal to active surface 


\section{Introduction}

Several non-reinforced crystalline thermoplastics, e.g. polyolefins, are exceptionally tough when loaded at moderate rates, but succumb to brittle fracture under impact - i.e. when loaded rapidly enough to exceed their static strength within about one second. This transition in behaviour is expressed as a rapid decline in fracture initiation resistance $G_{\mathrm{C}}$ as impact speed increases (Clutton and Channell (1995); Channell and Clutton (1996); Gensler et al. (2000); Rager (2003); Yu et al. (2004)) and in a rapid decline in dynamic fracture resistance $G_{\mathrm{D}}$ as crack speed increases to about 100-300 m/s (Wheel and Leevers (1993a)). There is usually a corresponding transition to a more brittle fracture surface. Here $G_{\mathrm{C}}$ and $G_{\mathrm{D}}$ represent, for each case, the local energy expenditure needed to overcome cohesion of the material across a unit-area plane.

These rate effects on fracture initiation and propagation are surely related, but the relationship can be established only when the underlying decohesion mechanisms are understood. Leevers (1995) proposed that in both cases the mechanism was the same: low-energy separation within a melt layer created by adiabatic heating.

The influence of adiabatic heating on the mechanical response of polymers - even at quite modest strain rates - has long been recognised. Engelter and Müller (1958) noted that the fraction $\beta$ of mechanical work converted to heat appeared to be smaller in polymers than in metals, but that the much lower thermal diffusivity and greater temperature sensitivity of polymers accentuated localised heating effects. In inherently localised deformation modes, e.g. necking and shear banding, very high temperatures can be generated. The elastic stress/strain localisation near a loaded crack front also generates a thermoelastic cooling which, though often disregarded, can amount to tens of K (Fuller et al. (1975), Bougaut and Rittel (2001)). More investigators, however, focused on dissipative heating. Different assumptions about the scale and shape of the plastically heated zone have been explored, and compared to results from increasingly sophisticated experimental techniques: from thermocouples (Döll (1976)) to infra-red detectors (Bjerke et al. (2002)). Because crystalline polymers are often opaque, and because the separation processes near observable free surfaces differ from those operating under plane strain conditions, experimenters have generally favoured glassy polymers. Nevertheless Haward (1994), Brough et al. (2004), Steenbrink et al. (1997) and others have noted evidence of local melting on polyethylene (PE) fracture surfaces.

Models which couple the effects of irreversible adiabatic heating back into the deformation process are well established for shear banding, but not so 
for fracture. Bjerke and Lambros (2003) did recognise the importance of heat generation within the craze active layer. They also noted, as Godovsky (1992) had done, that rupture of a stressed craze fibril can release strain energy and dissipate it during recoil. Because the fundamental micromechanisms of fracture in polymers are not well understood it seems paradoxical that adiabatic heating could contribute to them, because thermoplastics generally become less susceptible to brittle fracture with increasing bulk temperature. Williams and Hodgkinson (1981) modeled "thermal blunting” more intuitively, as a process which toughens polymers at high crack speeds and impact rates.

The adiabatic fracture model of Leevers (1995) is relatively uncomplicated but fully coupled. Adiabatic heating is not merely generated by a predefined cohesive process and then fed back to interfere with it; it defines the decohesion criterion, and thereby determines fracture resistance. The ultimate separation mechanism is visualised as low-energy disentanglement of polymer chains within a very thin melt layer. This layer has formed and thickened by adiabatic heating from a highly localised process in which inextensible craze fibrils are drawn through a thin active layer at the craze/bulk interface (Lauterwasser and Kramer (1979)). The loss of fracture resistance with increasing speed corresponds to a transition away from isothermal conditions in this layer and towards those in which there is a rate-dependent competition between adiabatic heating and conduction.

This idea was analysed by modelling the craze layer as a Dugdale-Barenblatt type, constant-stress, planar cohesive zone in a linearly elastic (Leevers (1996)) or non-linearly pseudoelastic (Leevers and Morgan (1995)) material. The thermal conduction analysis assumed conductivity and diffusivity to be independent of temperature.

Despite these limitations, the model yielded encouraging results. It explained the power-law decay of $G_{\mathrm{C}}$ with increasing impact speed $\dot{v}$ - essentially, $G_{\mathrm{c}} \propto \dot{v}^{-2 / 3}-$ observed for pipe grade PE and other thermoplastics (Leevers and Morgan (1995); Rager (2003)), and provided adequate quantitative estimates of $G_{\mathrm{C}}$ values from bulk properties only (Leevers (1996)). It also provided good estimates of $G_{\mathrm{D}}$, at speeds of $100 \mathrm{~m} / \mathrm{s}$ or so, as measured using a water pressurised pipe test (Greenshields and Leevers (1996)) or the high-speed double torsion test (Wheel and Leevers (1993a)).

Other observations cast the theory into question even when some of them seem to support it. Rager (2003) found that PMMA shows the expected inverse- $2 / 3$ power law speed dependence although this material lacks the well-defined 'structural collapse' (e.g. melting) temperature which the 
model needs. Rager (2003) even found that a thermosetting epoxy showed this speed dependence, although it neither melts nor has any finite dimension of structural cohesion (e.g. for thermoplastics, the extended chain length). Other apparently eligible thermoplastics, e.g. lower molecular weight polyethylenes, seem to show an essentially rate-independent fracture resistance (Leevers et al. (2000)). Further questions arise where changes in impact fracture resistance are achieved without changing bulk properties which the model recognises as influential. Rubber-toughened and microparticulate reinforced materials are probably outside the domain of the model, but the greater resistance of $\beta$-polypropylene than of $\alpha$ polypropylene to impact fracture (Tordjeman et al. (2001); Chen et al. (2002)) poses a real challenge: can adiabatic decohesion be sufficiently affected by the broader distribution of endotherms?

This paper presents a numerical method which can implement more realistic assumptions to more realistic materials. The method is applied, using three model thermoplastic polymers, to:

- a planar craze homogeneously extended at constant speed, as in the deeply, circumferentially, sharply notched tensile specimens used by Chan and Williams (1983), Pandya and Williams (2000), O'Connell et al. (2002) and others; and

- a Dugdale-Barenblatt crack-tip craze, under impact or (to a first approximation) rapidly-propagating conditions.

\section{Development and results of the original analysis}

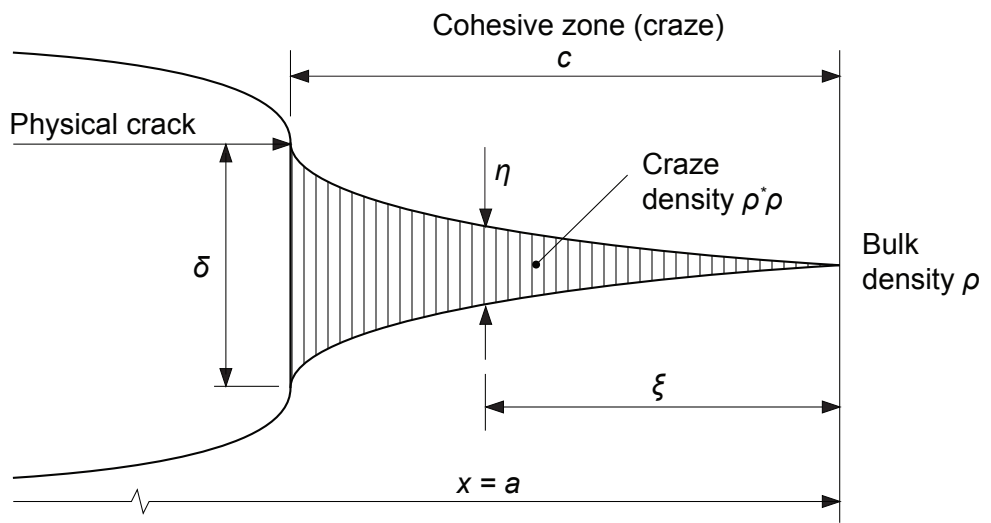

Fig. 1. Cohesive zone dimensions

The original analysis was based on a crack-tip Dugdale-Barenblatt zone (Fig. 1) - assumed to be much shorter than the crack - and on a very simple thermal model of the active layer region (Fig. 2a). The cohesive zone is sufficiently long and thin to be treated locally as one-dimensional, 

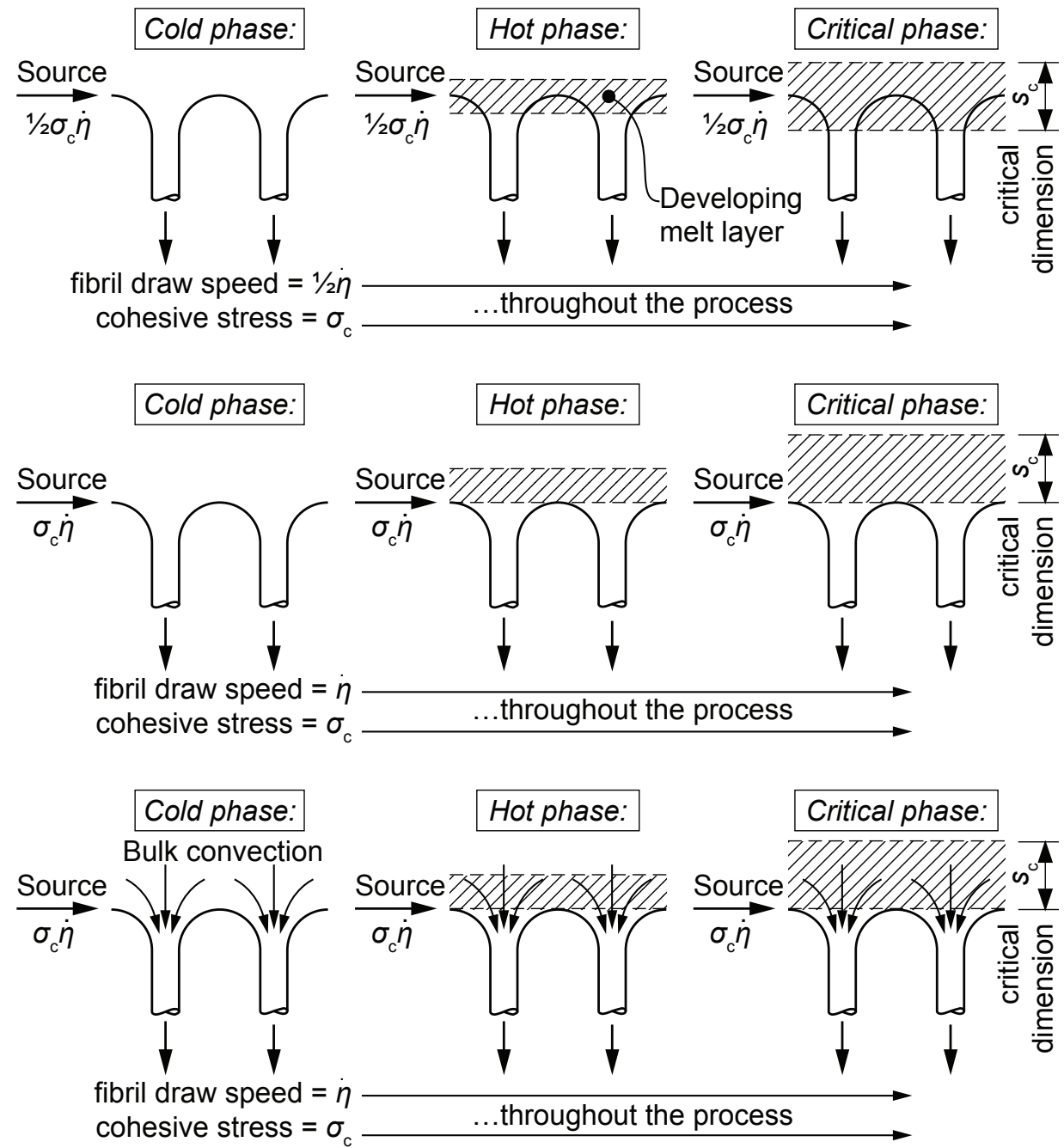

Fig. 2. Thermal models for the cohesive surface: (a) both cohesive surfaces active within a uniform medium, zero convection; (b) single active cohesive surface, semi-infinite medium, zero convection; (c) single active cohesive surface with convection.

both mechanically and thermally, in its through-thickness direction. The fibrils exist only mechanically, as inextensible members fixed at the cohesive zone midplane; their formation has not changed the bulk thermal properties. They draw material through each cohesive surface against a constant and uniform cohesive stress $\sigma_{\mathrm{c}}$ which arises from the creation of fibril surface free energy, from dissipation associated with the disentanglement needed to separate each fibril from its neighbours, and from plastic work done during subsequent stretching to an extension ratio $\lambda_{\text {F }}$. The total work appears as a planar heat source

$$
\dot{q}^{\prime \prime}=\beta \frac{\sigma_{\mathrm{c}}}{N_{\mathrm{a}}} \frac{\mathrm{d} \eta}{\mathrm{d} t}=\beta \frac{\sigma_{\mathrm{c}}}{N_{\mathrm{a}}} \dot{\eta}
$$

at each active surface, where $\eta$ is the cohesive zone thickness and $t$ is 
time. $N_{\mathrm{a}}$, the number of mechanically active cohesive surfaces ( 1 or 2 ), was assumed to be 1 and the thermomechanical efficiency $\beta$ to be unity: for crystalline polymers $\beta$ is usually is reported to be about 0.8-0.9 (Godovsky, 1992) though Pegoretti et al. (2004) have indicated much lower values.

Whether they draw symmetrically or not, the two cohesive surfaces are assumed to be thermally independent. Although there is thermal conduction away from each active cohesive layer, the temperature there increases to $T_{\mathrm{m}}$. After further heating, surfaces parallel to the active layer and some critical distance $s_{\mathrm{C}}$ (identified as a structural dimension of the material) apart also reach $T_{\mathrm{m}}$. The cohesive stress then instantaneously collapses. Since a real craze has a finite relative density $\rho^{*}$, some proportion of $\dot{q}^{\prime \prime}$ must also be convected into it by mass flow across the active layer, but this was accounted for only nominally: convection was assumed to balance conduction into the bulk material on the other side of the surface. This assumption will now be implemented via another symmetry variable $N_{\mathrm{z}}=2$, by requiring the critical temperature condition to be satisfied at $\pm s_{\mathrm{C}} / N_{\mathrm{Z}}$ from the active layer. $N_{\mathrm{Z}}=1$ identifies an alternative limiting case in which the craze has infinitesimal density and there is heat transfer only into the semi-infinite bulk material; the critical thermal condition must then be satisfied at $z=s_{c}$.

\section{Finite volume analysis}

The numerical model accounts for the factors discussed above, and can be used to isolate and investigate their effects in more detail for a nonlinear material - i.e one whose thermal or mechanical analysis cannot rely on superposition. The $z$ direction through each cohesive surface is represented using a one-dimensional finite-volume model (Fig. 3). It will be assumed that the number of active surfaces $N_{\mathrm{a}}=1$.

At the beginning of step 1, at time zero, the undeformed bulk polymer is homogeneous and isotropic has a uniform temperature $T=T_{0}$. At $t>0$ the craze material within $-\eta(t)<z<0$ has been stretched to a constant extension ratio $\lambda_{\mathrm{F}}$ (typically, 1-100) along the $z$ direction. Within the craze, $N_{\mathrm{F}}$ fibrils cross each unit area normal to $z$. Each fibril is pinned at surface 1 with an adiabatic or isothermal boundary condition, and is drawn from the bulk material to the right of surface 2. At time $t=0$, the two surfaces still coincide and a linear array of cells, each initially $L_{0}$ long and at temperature $T=T_{0}$, extends from surface 2 into the bulk material.

For a constant thickening rate $\dot{\eta}=V_{\mathrm{c}}$ as the cohesive surfaces begin to separate, each cell in turn is stretched to $\lambda_{\mathrm{F}}$ in time $\Delta t=\lambda_{\mathrm{F}} L_{0} / V_{\mathrm{c}}$. Under 

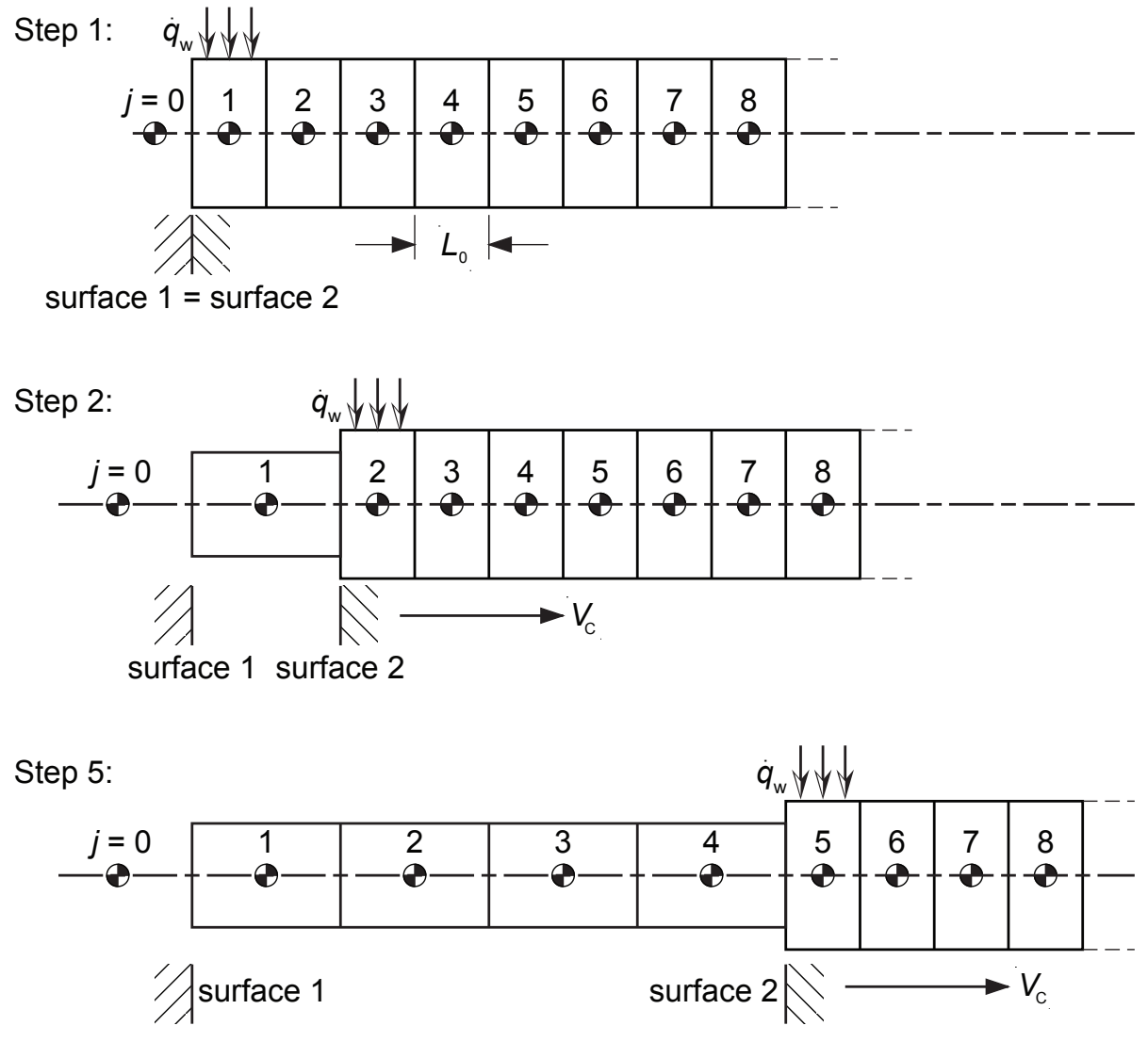

Fig. 3. Finite volume model of fibril drawing at a speed $V_{\mathrm{C}}$

impact loading, the craze thickening speed is increased according to the cell number $j$ :

$$
\dot{\eta}=\frac{\eta_{\mathrm{j}}-\eta_{\mathrm{j}-1}}{t_{\mathrm{j}}-t_{\mathrm{j}-1}}=\left(\frac{\ddot{\eta} L_{0}}{2 \rho^{*}}\right)^{1 / 2} \frac{1}{(j)^{1 / 2}-(j-1)^{1 / 2}}
$$

To maintain stability, the time step is re-adjusted for each cell.

At the craze surface there is initially a planar heat source $\beta \sigma_{\mathrm{c}} \dot{\delta}$ (Eqn. (1)) per unit area per unit time, where $0<\beta \leq 1$ and $\sigma_{\text {c }}$ (typically 20-50 $\mathrm{MPa}$ ) are parameters. When the surface temperature reaches the nominal melting temperature $T_{\mathrm{m}}$ a melt layer forms. Its growth consumes a latent heat of fusion $\Delta H_{\mathrm{f}}$ which can be interpreted as the mechanical work needed to pull crystallites apart. The remaining work transferred across the melt/bulk interface at step $j$ is therefore dissipated as a heat source:

$$
\dot{q}_{\mathrm{wj}}=\beta\left(\sigma_{\mathrm{c}} \lambda_{\mathrm{F}}-N_{\mathrm{j}-1} \Delta H_{\mathrm{f}}\right) L_{0}
$$

where $N_{\mathrm{j}-1}$ is the number of cells that have melted at step $j-1$. The analysis determines the decohesion time $t=t_{\mathrm{dc}}$, expected to be less than $1 \mathrm{~ms}$, at which the melt layer has reached a thickness $s_{\mathrm{C}}$. 
Temperatures are defined at the centre of each cell, and calculated from heat exchanges $q$ at its surfaces during a time increment chosen for stability to be

$$
\delta t<\frac{L_{0}^{2}}{2 \kappa} \ll \Delta t
$$

where $k$ is the bulk thermal diffusivity. The contributions considered are:

- Heat conducted along the fibril axis $(z)$ direction according to

$$
q=-\frac{\mathrm{d}}{\mathrm{d} z}(k A T)
$$

where $A(z)$ is the cross-sectional area occupied by solid, and the bulk thermal conductivity $k$ depends also on $T$ and on extension $\lambda$.

- Surface heat loss from the fibril surface:

$$
q=-h A_{\mathrm{S}}\left(T-T_{0}\right)
$$

where $h$ is a surface heat transfer coefficient and $A_{\mathrm{S}}$ is the circumferential surface area of all cells at that position. Each cell is here is assumed to have stretched to a length $\lambda_{F} L_{0}$ at constant volume, giving it a characteristic circumference $4 / \sqrt{N \lambda_{\mathrm{F}}}$. The surface heat transfer rate to all $N$ elements is therefore given for $\lambda_{\mathrm{F}}>1$ by

$$
q=-4 h L_{0}\left(T-T_{0}\right)\left(N \lambda_{\mathrm{F}}\right)^{1 / 2}
$$

- Heat generated by the dissipation of mechanical work according to Eqn. (3).

The cell temperature is updated from the net heat flow over $\delta t$ (see Appendix), using look-up tables representing piecewise-linear functions of enthalpy per unit volume - excluding fusion peaks which are treated separately as in Eqn. (3).

Three model materials were investigated here. All three loosely resemble a commercial, modified high-density pipe-grade ethylene copolymer, whose impact and RCP resistance is of industrial importance. All have a structural dimension $s_{\mathrm{C}}=2 \mu \mathrm{m}$, which corresponds to a typical weight-average chain length, and an enthalpy $\Delta H=\rho C_{\mathrm{p}}=2.4 \mathrm{MJ} \mathrm{m}^{-3} \mathrm{~K}^{-1}$ where $\rho$ and $C_{\mathrm{p}}$ are the mass density and specific heat of the bulk material.

- Material PE-A has an enthalpy of fusion $\Delta H_{\mathrm{f}}$ of about $130 \mathrm{MJ} \mathrm{m}^{-3}$ at a melting temperature $T_{\mathrm{m}}=138 \mathrm{C}$.

- Material PE-B is a hypothetical ' $\beta$-PE' derived from PE-A, whose phase transformation enthalpy has been equally distributed between the melting peak up to $138 \mathrm{C}$ and a secondary peak at around $70 \mathrm{C}$.

- Material PE-L is Material PE-A without a latent heat of fusion. 


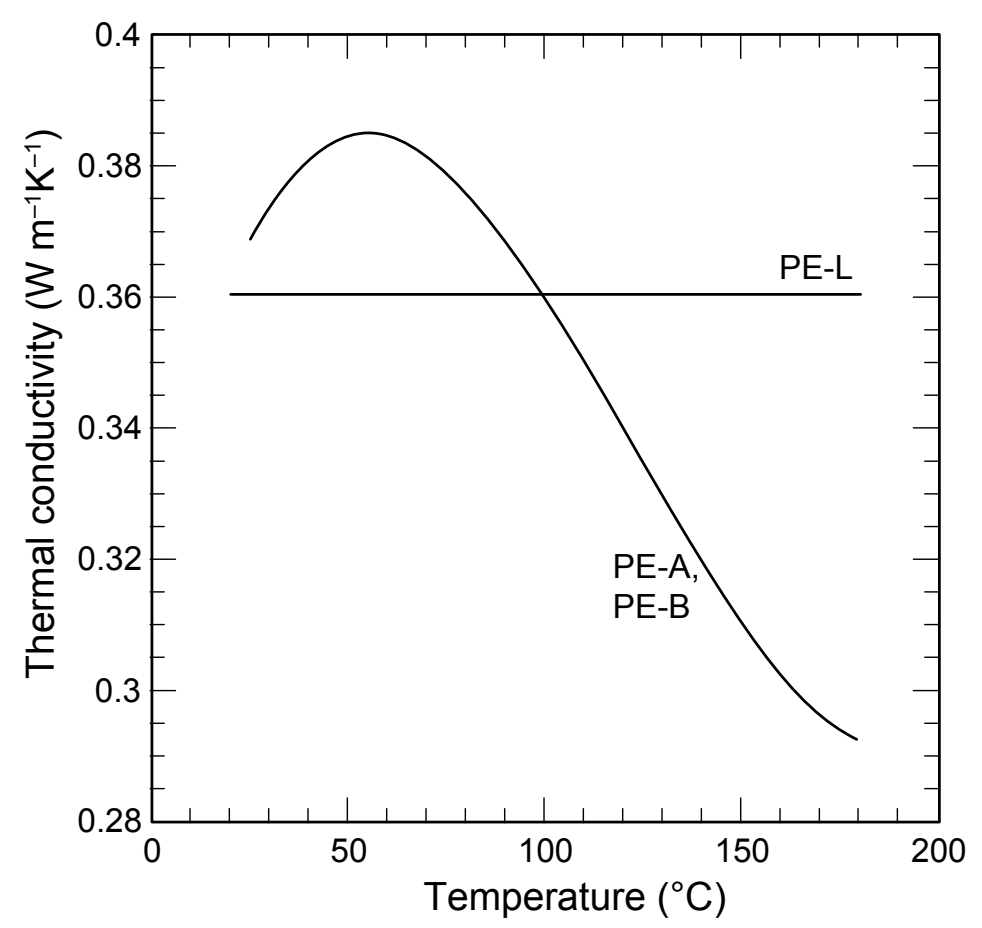

Fig. 4. Thermal conductivity of model polymers

Thermal conductivity data $k(T)$ for the bulk materials are shown in Fig. 4. The linear dependence of $k$ on stretch reported by Godovsky (1992) was assumed here for all model materials, linear and non-linear: it simplifies and accelerates solution by allowing stretched and unstretched regions to use the same time step. However, thermal conduction within the craze does not strongly influence the results. Thermomechanical efficiency $\beta$ is here treated as constant for each material, although the method does not preclude consideration of strain or strain-rate dependency as observed by Rittel (1999) and others.

After $\Delta t / \delta t$ time steps the active cell has emerged completely into the fibril and the cohesive surface has advanced into the next cell. The temperature field is reviewed and, if $T>T_{\mathrm{m}}$, the melt front is located. When the melt front reaches the critical distance the simulation is terminated, the decohesion time $t_{\mathrm{dc}}$ recorded and the surface energy (i.e. the effective fracture resistance) calculated as the product of cohesive stress and total opening displacement.

Each result must be monitored carefully to ensure that the energy balance has been maintained. Specifying excessive precision at the outset, by demanding a cell size much smaller than the critical structural dimension $s_{\mathrm{C}}$, can result in unacceptable computation time and accumulation of roundoff errors. Finite volume formulation permits a running check on solution accuracy: after each cell has emerged completely from the substrate sur- 
face, the heat content of the whole cell array is computed and compared to the total mechanical work input obtained by adding the values of $\dot{q}_{\mathrm{wj}}$ from Eqn. (3) at each step - minus the total latent heat of fusion. If this is not within $1 \%$ of the specified thermomechanical efficiency $\beta$ at the conclusion of the calculation, the cell size is readjusted and the simulation begins again. Energy balances were usually maintained to within $0.1 \%$.

\section{Analytical solutions}

The analytical solutions, based on linear superposition, on which the model was based are here extended to provide new results and - firstly - to provide idealised test cases for the numerical analysis.

\subsection{Constant craze thickening rate}

The assumption of constant craze thickening rate represents the fullnotch tension impact experiments of Leevers et al. (2003), in which a fullsection craze layer is formed slowly and then rapidly extended at constant rate. Analytical solutions are available for two limiting cases, for craze densities $\rho^{*} \equiv \lambda_{\mathrm{F}}^{-1}$ of 0 and 1 .

\subsubsection{Full density craze}

In physical terms, the work done by cohesive stress in this case is dissipated wholly in creating the lateral surfaces of the fibrils - i.e. in disentanglement. The separated fibrils are not plastically extended and remain packed in a mass which has identical thermal properties to those of bulk material. Thus material flows at a constant speed $V_{\mathrm{c}}$ over a plane heat source of intensity defined according to Eqn. (1) as

$$
\dot{q}^{\prime \prime}=\frac{\beta \sigma_{\mathrm{c}} V_{\mathrm{c}}}{N_{\mathrm{a}}}
$$

The analytical solution to this problem (Carslaw and Jaeger (1959)) is

$$
\Delta T=\frac{\dot{q}^{\prime \prime}}{\rho C_{\mathrm{p}} V_{\mathrm{c}}} \exp \left(\frac{V_{\mathrm{c}}}{\kappa} z\right)
$$

for $z>0$ and

for $z<0$.

$$
\Delta T=\frac{\dot{q}^{\prime \prime}}{\rho C_{\mathrm{p}} V_{\mathrm{c}}}
$$




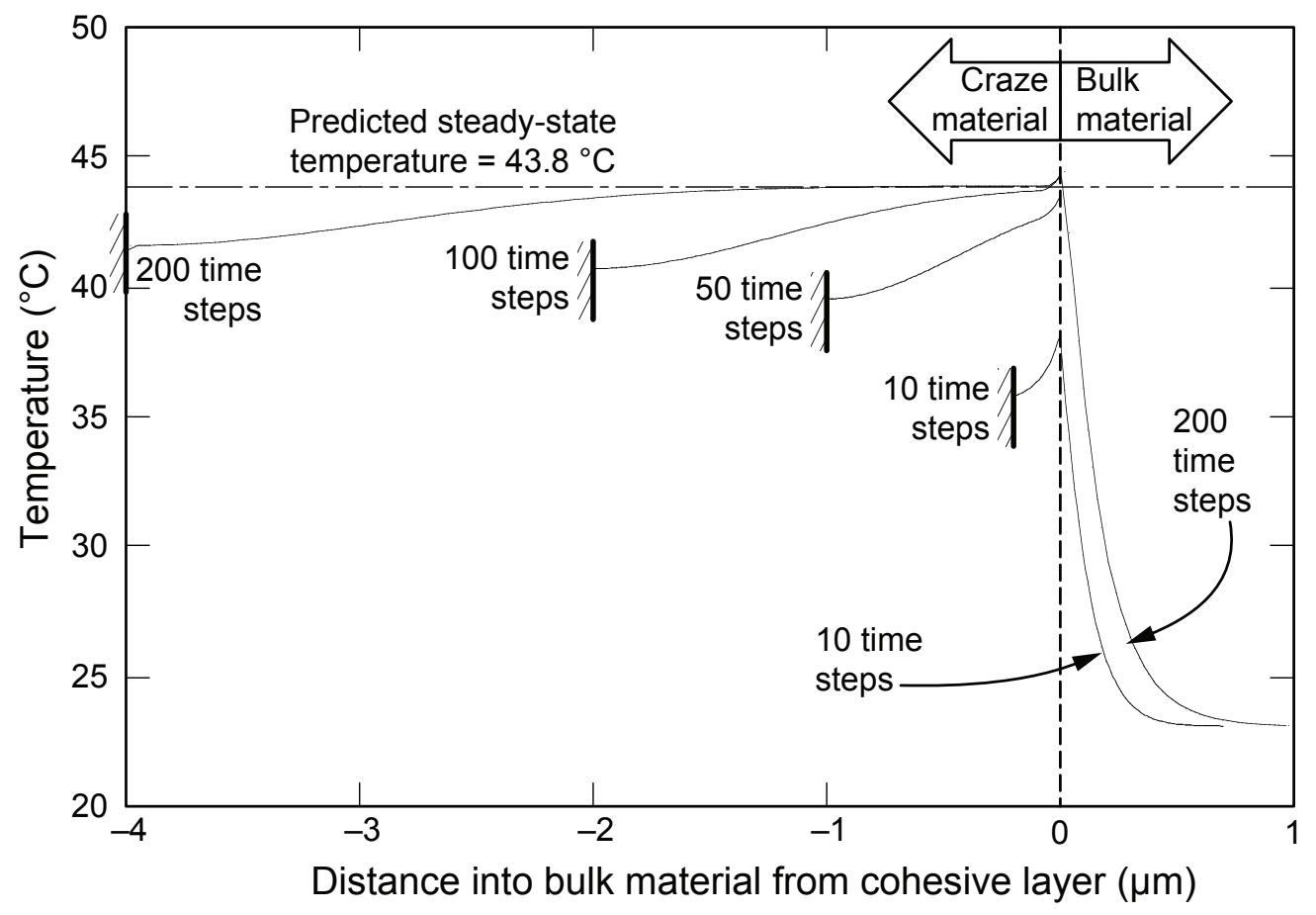

Fig. 5. Temperature distribution in the craze and bulk regions: unit fibril stretch test case

Figure 5 shows the computed temperature distribution around the source after 10, 50, 100 and 200 cells have crossed it. The unstretched cell size is $20 \mathrm{~nm}$ and the time step $0.2 \mathrm{~ns}$, i.e. each cell takes 100 relaxation time steps to cross the cohesive layer. The cohesive stress is $50 \mathrm{MPa}$, the craze thickening rate $1.0 \mathrm{~m} / \mathrm{s}$ and $\beta=1$ is assumed so that the rate of heat input to the single active surface is $\dot{q}^{\prime \prime}=50 \mathrm{MW} \mathrm{m}^{-2}$. Here the boundary condition at the other fibril root (i.e. the 'inactive' cohesive surface) is represented as an adiabatic wall, but after 200 time steps its effect is no longer seen at the active layer, where the temperature increase has stabilised at a value very close to the predicted $43.8 \mathrm{C}$. The predicted exponential decay of temperature over a characteristic distance of $\kappa / V_{\mathrm{c}}=150 \mathrm{~nm}$ into the bulk material is very accurately represented, validating the numerical model and emphasising the small length scales involved.

\subsubsection{Zero density craze}

This case, shown schematically in Fig. 2(b), is closely related to the original model of Fig. 2(a): the craze exerts a stress, but has negligible volume. For a specified finite craze thickening rate $V_{\mathrm{c}}$, the thermal problem reduces to that of a static semi-infinite domain heated on its surface by the constant source of Eqn. (8), where $N_{\mathrm{z}}=1$ because only one direction from the active layer is thermally conductive. Carslaw and Jaeger (1959) (p75) give 
the time evolution of temperature at $z$ :

$$
\Delta T=\frac{2 \dot{q}^{\prime \prime}}{\rho C_{\mathrm{p}}}\left\{\left(\frac{t}{\pi \kappa}\right)^{1 / 2} \exp \left(\frac{-z^{2}}{4 \kappa t}\right)-\frac{z}{2 \kappa} \operatorname{erfc} \frac{z}{2 \sqrt{\kappa t}}\right\}
$$

where $\operatorname{erfc}(x)$ is the complementary error function. Equation (10) can now be used to implement a decohesion criterion. Decohesion is assumed to occur if, at time $t_{\mathrm{dc} 0}$, the temperature $T$ at the critical distance $z=s_{\mathrm{c}} / N_{\mathrm{z}}$ from the active surface has increased from its initial value $T_{0}$ to the melt temperature $T_{\mathrm{m}}$. On defining a decohesion Fourier number

$$
F o_{\mathrm{dc}}=\frac{4 \kappa t_{\mathrm{dc} 0} N_{z}^{2}}{s_{\mathrm{C}}^{2}}
$$

we obtain

$$
\left(\frac{F \boldsymbol{O}_{\mathrm{dc}}}{\pi}\right)^{1 / 2} \exp \left(-\frac{1}{F \boldsymbol{O}_{\mathrm{dc}}}\right)-\operatorname{erfc}\left(\frac{1}{F \boldsymbol{o}_{\mathrm{dc}}^{1 / 2}}\right)=\frac{N_{\mathrm{a}} N_{\mathrm{z}}^{2} \kappa \rho C_{\mathrm{p}}\left(T_{\mathrm{m}}-T_{0}\right)}{\beta \sigma_{\mathrm{c}} V_{\mathrm{c}} S_{\mathrm{c}}}
$$

The numerical procedure inverts Eqn. (12) to estimate a decohesion time $t_{\mathrm{dc} 0}$. This value is then used to choose a cell size to give the desired resolution on calculated decohesion time $t_{\mathrm{dc}}$ for non-zero craze density.

\subsection{Linearly increasing craze thickening rate for zero density craze}

Using the Dugdale-Barenblatt model, it can be shown that a small (length $c \ll a)$ crack-tip craze with constant and uniform cohesive stress will thicken at a rate which increases linearly with load-point displacement time $t$, so that

$$
\ddot{\eta}=\frac{E^{\prime}}{\sigma_{\mathrm{c}}} \Gamma_{\mathrm{v}}\left(\frac{a}{W}\right)\left(\frac{\xi}{c}\right)^{1 / 2} \frac{\dot{v}^{2}}{W}
$$

where $0 \leq a ł W$ is the crack extension along a path length (defining the specimen size) $W$, where $0 \leq \xi \leq c$ is the distance from the craze tip to the crack tip, $W$ the specimen size (crack path length) and

$$
\Gamma_{\mathrm{V}}\left(\frac{a}{W}\right) \equiv \frac{B}{B_{\mathrm{c}}} \frac{1}{C^{* 2}} \frac{\mathrm{d} C^{*}}{\mathrm{~d} a / W}
$$

is a non-dimensional form of the Irwin-Kies crack driving force $G$ under controlled displacement $v$ :

$$
G=\frac{E^{\prime}}{2 W} \Gamma_{\mathrm{v}}\left(\frac{a}{W}\right) v^{2}
$$

$E^{\prime}$ being the reduced tensile modulus and $C^{*}=E^{\prime} B C$ being a dimensionless form of the load-point compliance $C . B$ is the specimen thickness and 
$B_{\mathrm{C}} \leq B$ are the specimen thickness and crack path width. The craze length increases linearly with $G$, but will here be assumed to remain small enough to leave $C$ unaffected.

On transforming Eqn. (13) into a heat source intensity via Eqn. (1), the evolution of the temperature field becomes (Carslaw and Jaeger (1959)):

$$
\Delta T(z, t)=\frac{1}{N_{\mathrm{z}} \rho C_{\mathrm{p}}(\pi \kappa)^{1 / 2}} \int_{0}^{t} \exp \left[-\frac{z^{2}}{4 \kappa(t-u)}\right] \frac{\dot{q}^{\prime \prime}(u)}{(t-u)^{1 / 2}} \mathrm{~d} u
$$

Clearly $\ddot{\eta}$ is greatest at the crack tip $\xi=c$, where

$$
\dot{q}^{\prime \prime}=\beta \frac{\sigma_{\mathrm{c}} \ddot{\eta}}{N_{\mathrm{a}}} t=\beta \frac{E^{\prime}}{N_{\mathrm{a}}} \Gamma_{\mathrm{v}}\left(\frac{a}{W}\right) \frac{\dot{v}^{2}}{W} t
$$

which is independent of the cohesive stress. After some manipulation, the temperature distribution becomes

$$
\Delta T(z, t)=\frac{1}{6 \pi^{1 / 2} N_{\mathrm{a}} N_{\mathrm{z}}} \frac{\beta E^{\prime} z^{3}}{\rho C_{\mathrm{p}} \kappa^{2}} \Gamma_{v}\left(\frac{a}{W}\right) \frac{\dot{v}^{2}}{W} \mathrm{I}(F o)
$$

where $F o$ is the Fourier number $F o=\frac{4 \kappa t}{z^{2}}$ and

$$
\mathrm{I}(F o)=F \boldsymbol{O}^{1 / 2}(F o+1) \exp \left(-\frac{1}{F o}\right)-\left(1+\frac{3}{2} F o\right) \pi^{1 / 2} \operatorname{erfc}\left(\frac{1}{F o^{1 / 2}}\right)
$$

The adiabatic decohesion criterion is now applied again as in §4.1.2, and the impact velocity corresponding to a given $F o_{\text {dc }}$ can be calculated by writing Eqn. (17) in the form

$$
\dot{v}=\left[\mathrm{I}\left(F o_{\mathrm{dc} 0}\right)\right]^{-1 / 2} \dot{v}_{0}
$$

where $\dot{v}_{0}$ is a reference impact speed given by

$$
\dot{v}_{0}^{2}=6 \pi^{1 / 2} N_{\mathrm{a}} N_{\mathrm{z}} \rho C_{\mathrm{p}} \kappa^{2}\left(T_{m}-T_{0}\right) \frac{W}{\beta E^{\prime} S_{\mathrm{c}}^{3} \Gamma_{v}\left(\frac{a}{W}\right)}
$$

The local decohesion condition is now assumed to precipitate unstable fracture - an assumption whose validity depends on the geometrical stability properties of the specimen. Thus $G=G_{\mathrm{c}}$ when $t=t_{\mathrm{dc}}$ and, since $v=\dot{v} t, G_{\mathrm{c}}$ can be determined from Eqn. (19) using Eqn. (14):

$$
G_{\mathrm{c}}=\frac{3 \pi^{1 / 2} N_{\mathrm{a}} N_{\mathrm{z}}}{16}\left[\frac{F o_{\mathrm{dc} 0}^{2}}{\mathrm{I}\left(F o_{\mathrm{dc} 0}\right)}\right] \frac{\rho C_{\mathrm{p}}\left(T_{m}-T_{0}\right)}{\beta} s_{\mathrm{c}}
$$


Equation (21) concludes the argument through which Eqn. (1) has been applied to a material whose strength collapses at $T=T_{m} . G_{\mathrm{c}}$ may now be predicted for specific material properties, specimen geometry and impact speed: Eqns. (11) to (21) are evaluated in succession from a chosen decohesion time $t_{\mathrm{dc} 0}$, which is the easiest parameter to estimate. Note that $\mathrm{I}(F o)$ reduces to $F^{3 / 2}$ as the Fourier number becomes large; this will predict that $G_{\mathrm{C}} \propto \dot{v}^{-2 / 3}$ at impact speeds $\dot{v} \ll \dot{v}_{0}$ :

$$
G_{\mathrm{C}}=E^{\prime-1 / 3}\left[\frac{3}{8} N_{\mathrm{a}} N_{\mathrm{z}} \frac{\rho C_{\mathrm{p}}\left(T_{\mathrm{m}}-T_{0}\right)}{\beta}\right]^{4 / 3}(\pi \kappa)^{2 / 3}\left[\frac{1}{2} \Gamma_{\mathrm{v}}(\alpha)\right]^{-1 / 3} W^{1 / 3} \dot{v}^{-2 / 3}
$$

as shown in Leevers (1996) and elsewhere. Some impact fracture test methods, particularly for high speeds, measure $t_{\mathrm{dc} 0}$ directly as a function of impact speed, computing $G_{\mathrm{C}}$ only later, indirectly and with difficulty (Rager (2003)). In this case Eqns. (11) and (21) can be applied directly.

\section{Results}

Using the more general numerical model, results for realistic model materials will be presented and compared (where appropriate) with those from analysis. All simulations assume a single active cohesive surface $\left(N_{\mathrm{a}}=1\right)$, an initial temperature $T=23 \mathrm{C}$ and - since surface heat transfer from craze fibrils soon proved to be insignificant $-h=0$. To simulate cracktip craze extension in impact, further parameters were given values typical of ISO 17281 impact fracture tests on PE bend specimens: a dynamic tensile modulus $\left(E^{\prime}=1 \mathrm{GPa}\right)$, a specimen-shape dependent normalised crack driving force $\left(\Gamma_{\mathrm{v}}=0.1\right)$, and a specimen size $(W=12 \mathrm{~mm})$.

\subsection{Validation of the numerical method}

The numerical method was validated using results for the linear material PE-L. Figure 6 shows results from simulations at a constant craze thickening rate of $1 \mathrm{~m} / \mathrm{s}$ and at an impact speed of $1 \mathrm{~m} / \mathrm{s}$. Typical limiting values of cohesive stress have been chosen. As the craze density $\rho^{*}$ tends to zero, there is excellent convergence to the zero-density decohesion times $t_{\mathrm{dc} 0}$ from Eqn. (12) and Eqn. (17), respectively, which are shown in Fig. 6 as points on the $\rho^{*}=0$ axis for each cohesive stress.

For a small crack-tip craze under impact loading (Fig. 6b), the decohesion time of the linear analysis is independent of the cohesive stress, since as cohesive stress increases, craze thickening rate for a given impact speed 

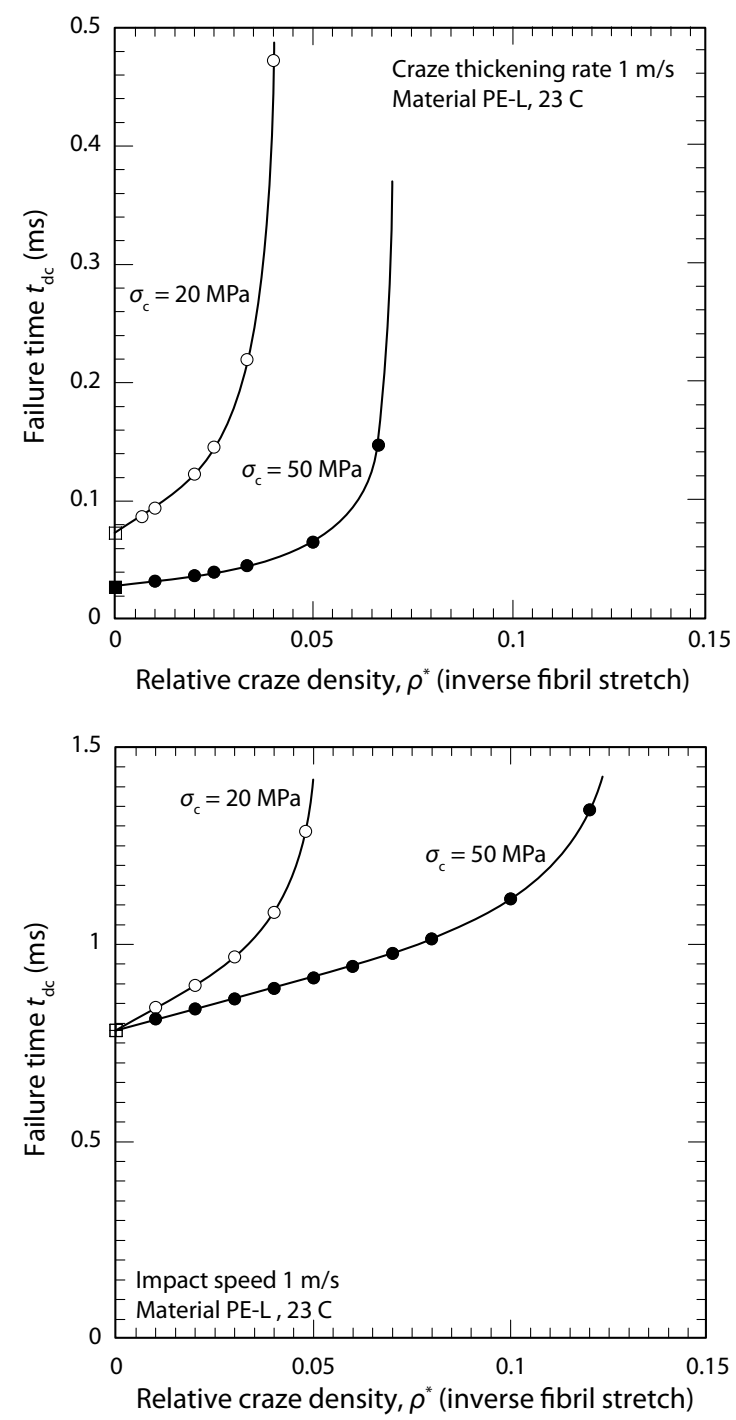

Fig. 6. Decohesion time for a linear material (PE-L) and at $20 \mathrm{MPa}$ and $50 \mathrm{MPa}$ cohesive stress, as a function of craze density, for (a) a constant thickening speed and (b) an impact speed of $1 \mathrm{~m} / \mathrm{s}$. Square points on the failure time axis show the analytical predictions.

decreases (Eqn. (13)), and therefore the heat source of Eqn.(1) remains unchanged. Fracture tests on polymers which fail by thermal decohesion become non-conservative if the craze does not remain small (Leevers and Morgan (1995)); we see here that increasing craze density has a similar effect because the fibrils draw away more thermomechanical heat. The lower the cohesive stress, the lower the craze density must be for adiabatic decohesion to threaten its lifetime, but the corresponding true fibril stress $\sigma_{\mathrm{c}} / \rho^{*}$ remains sustainable by even a hot PE fibre (Smith (1999)).

Figure 7 shows the effect of constant craze thickening rate. Again, the computed results show the same trends as the analytical ones, especially 

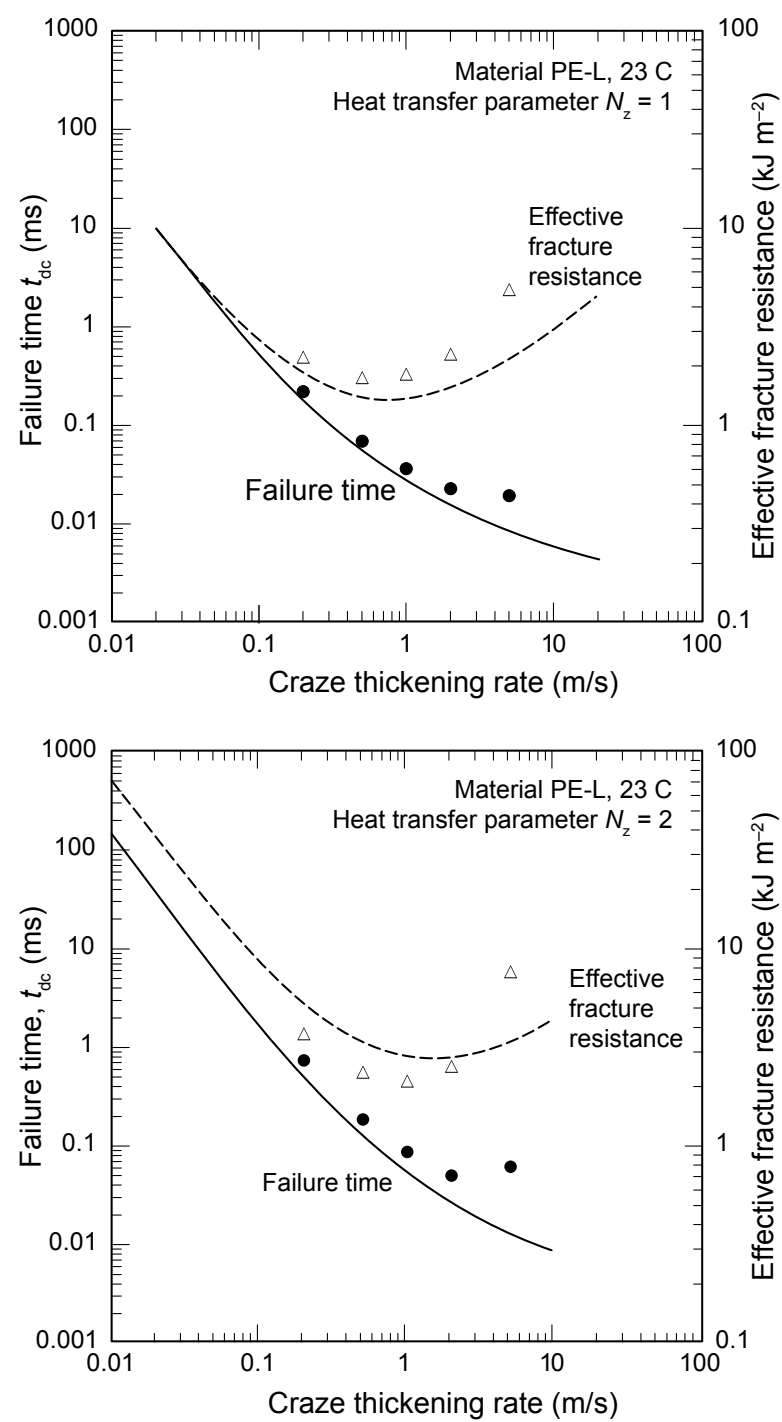

Fig. 7. Decohesion time and surface work vs. constant craze thickening rate for PE-L at 50 MPa cohesive stress for a craze density of 2\% (points); model compared to analytical results of Eqn. (12) (lines) (a) for semi-infinite domain analytical solution $N_{\mathrm{Z}}=1$ and (b) for infinite domain analytical solution $N_{\mathrm{Z}}=2$.

if the 'semi-infinite medium' option (i.e. $N_{\mathrm{z}}=1$ ) is chosen as a reference (Fig. 6). As expected, the computed decohesion times exceed the analytical ones due to heat loss into the craze.

\subsection{Effect of material endotherms}

Figure 8 compares temperature histories for linear (PE-L) and non-linear (PE-A) materials respectively (for a craze density of $5 \%$ and at $50 \mathrm{MPa}$ cohesive stress) at a constant craze thickening rate. For this intermediate thickening rate of $1 \mathrm{~m} / \mathrm{s}$, cohesive surface heating is at first hardly de- 


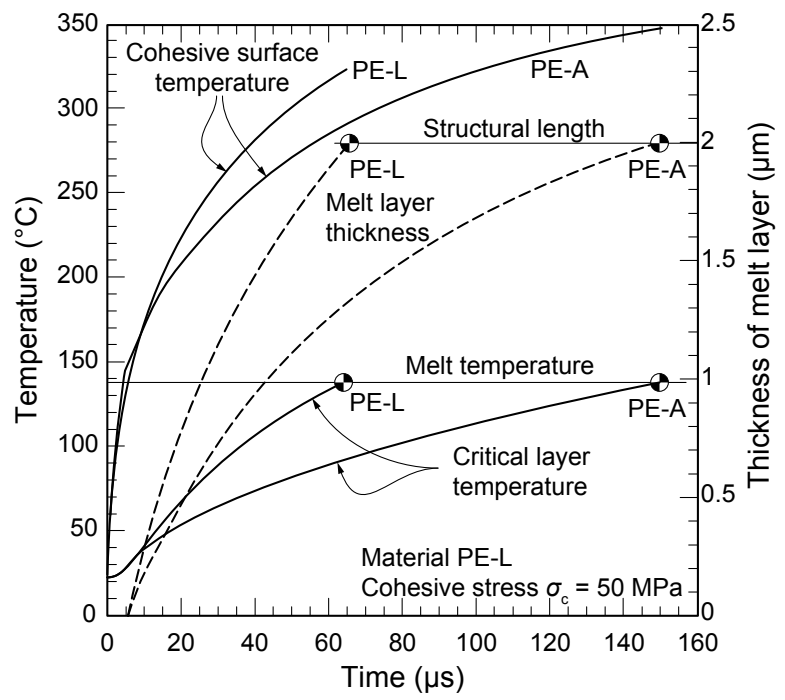

Fig. 8. Computed temperature and melt layer thickness histories at a constant thickening rate of $1 \mathrm{~m} / \mathrm{s}$ for PE-L and PE-A, with craze densities of 5\% and 50 MPa cohesive stress.

tected at the critical layer. Then, the temperature of the cohesive layer continues to rise while a melt layer forms and thickens around it. The melt front approaches and finally engulfs the critical surface, triggering decohesion.

Figures 9 and 10 present temperature/time plots for all three materials at impact speeds of 1 and $5 \mathrm{~m} / \mathrm{s}$, respectively, at $50 \mathrm{MPa}$ cohesive stress and for a relative craze density of $5 \%$. Under constant thickening rate, the melt layer appears quickly and thickens relatively slowly (Fig. 8), whereas at an impact speed of $1 \mathrm{~m} / \mathrm{s}$ (Fig. 9) its creation, thickening and decohesion are completed within the last 30\% of the decohesion time. On increasing the impact speed to $5 \mathrm{~m} / \mathrm{s}$ (Fig. 10) adiabatic heating is intensified and the melt temperature is reached much more quickly, but melt layer thickening remains relatively slow and becomes the overall rate-determining process.

The enthalpy of fusion and temperature-dependent thermal conductivity of material PE-A do not qualitatively change its craze decohesion behaviour from that of material PE-L. However, the decohesion time is extended - for a constant thickening rate of $1 \mathrm{~m} / \mathrm{s}$ it is more than doubled (Fig. 8). For the material PE-A, the temperature histories reveal a subtle levelling-off as the melting peak is approached, and for material PE-B also as the previous beta peak is encountered at $70 \mathrm{C}$ (the histories for PE-B at constant thickening rate are similar to those of PE-A, with an increase in decohesion time of just 3\%).

Table 1 differentiates the effects of single (PE-A) and double (PE-B) enthalpy peaks (of equal total enthalpy) on impact fracture resistance at the same 

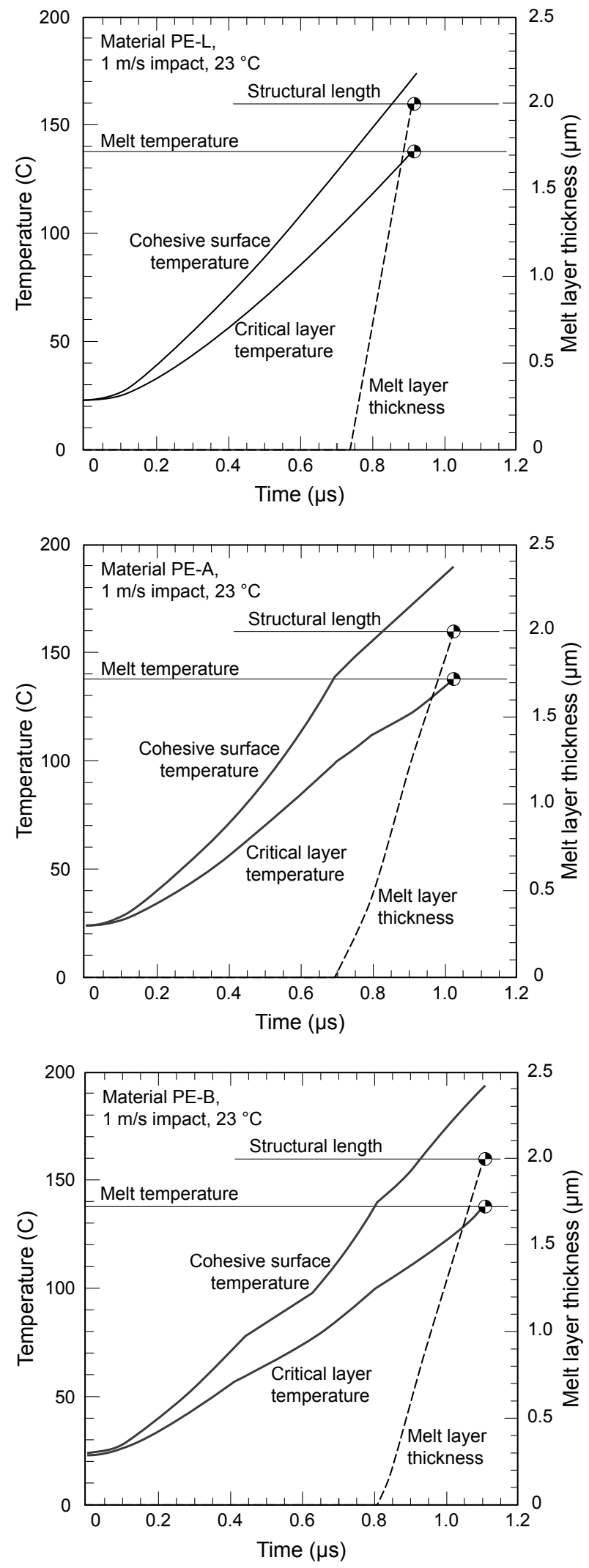

Fig. 9. Computed temperature and melt layer thickness histories at the craze mouth for three model materials with a craze density of 5\%, at $50 \mathrm{MPa}$ cohesive stress and an impact speed $1 \mathrm{~m} / \mathrm{s}$. 

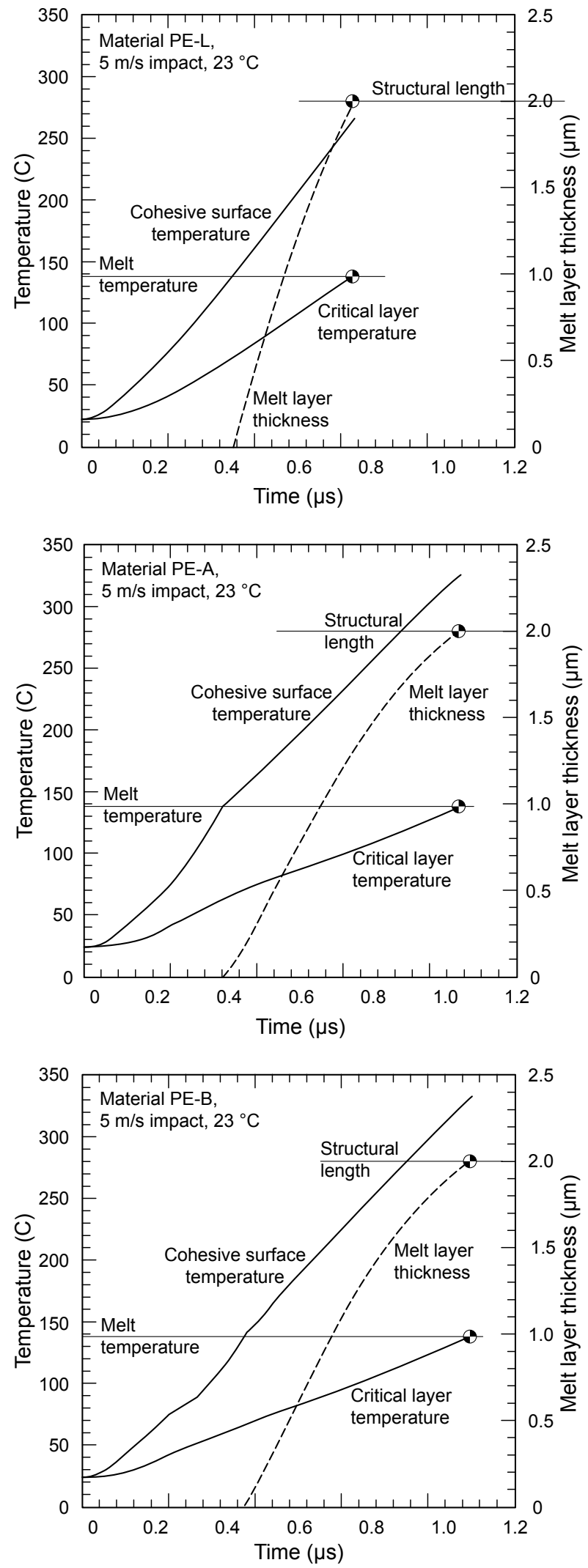

Fig. 10. Computed temperature and melt layer thickness histories at the craze mouth for three model materials with a craze density of 5\%, at $50 \mathrm{MPa}$ cohesive stress and an impact speed $5 \mathrm{~m} / \mathrm{s}$. 
Table 1

Influence of impact speed and material properties on predicted decohesion time and impact fracture resistance at $50 \mathrm{MPa}$ cohesive and for a 5\% craze density.

$$
1 \mathrm{~m} / \mathrm{s} \quad 5 \mathrm{~m} / \mathrm{s}
$$

\begin{tabular}{ccccc} 
Material & $\begin{array}{c}\text { Decohesion } \\
\text { time } \\
(\mu \mathrm{s})\end{array}$ & $\begin{array}{c}\text { Fracture } \\
\text { resistance } \\
\left(\mathrm{kJ} / \mathrm{m}^{2}\right)\end{array}$ & $\begin{array}{c}\text { Decohesion } \\
\text { time }\end{array}$ & $\begin{array}{c}\text { Fracture } \\
\text { resistance } \\
(\mu \mathrm{s})\end{array}$ \\
\hline PE-L & 917 & 3.5 & 157 & 2.6 \\
PE-A & 1027 & 3.9 & 218 & 4.2 \\
PE-B & 1101 & 4.0 & 226 & 4.3 \\
\hline
\end{tabular}

two speeds: $1 \mathrm{~m} / \mathrm{s}$ and $5 \mathrm{~m} / \mathrm{s}$. Clearly enthalpy peaks have much more influence on fracture time when the impact speed is high and the melt layer thickening process becomes rate-determining. Because convection into a Dugdale-Barenblatt-Lauterwasser-Kramer craze increases linearly with time, each hesitation in heating rate caused by an endotherm might delay the onset of local melting enough for convection to overwhelm the source. A 'high' speed of $5 \mathrm{~m} / \mathrm{s}$ was chosen for illustration because at 7 $\mathrm{m} / \mathrm{s}$ the critical condition is never achieved at all. However, the specific form of the fusion endotherm - as a single peak in material PE-A or two widely spaced peaks in material PE-B - appears to have little effect.

\subsection{Effect of molecular weight}

It is interesting to explore the effect of simultaneously varying critical dimension and fibril stretch ratio according to their dependences on an equivalent molecular weight. Increasing molecular weight increases the structural dimension (thereby increasing decohesion time) but also increases chain extensibility (thereby decreasing convective heat loss and decreasing decohesion time). For the time being cohesive stress $\sigma_{\mathrm{c}}$ is treated as an independent variable, though at least for some polymers it can be measured directly (Leevers et al. (2000)).

For monodisperse PE with a monomer molecular weight of $14 \mathrm{~g} \mathrm{~mol}^{-1}$, a backbone bond length of $0.15 \mathrm{~nm}$ and angle of $120^{\circ}$, the extended chain length $s$ in $\mathrm{nm}$ is

$$
s=\frac{M}{14} \times 0.127
$$

The extensibility of a chain segment, defined as the ratio of the extended chain length of molecular weight $M$ to the end-to-end distance of a long, 
coiled chain of same molecular weight, is

$$
\lambda_{\max }=\left(\frac{M}{14 C_{\infty}}\right)^{1 / 2}
$$

where for PE the characteristic ratio, $C_{\infty}$, is equal to 6.7 so that $\lambda_{\max } \approx$ $0.1 M^{1 / 2}$. The meaning of 'segment' in this context will be discussed in $\S 6.1$.

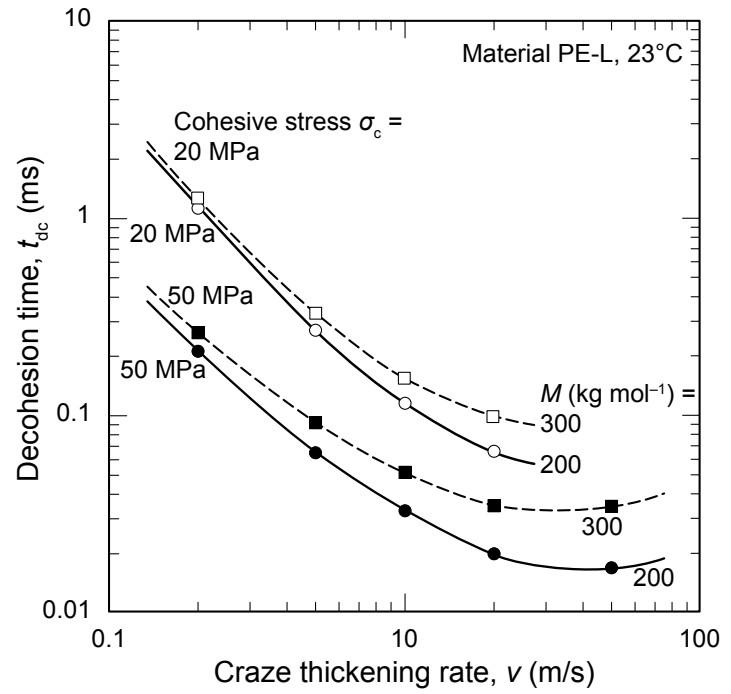

Fig. 11. Computed decohesion time as a function of constant craze thickening rate for two effective molecular weights of 200 and $300 \mathrm{~kg} \mathrm{~mol}^{-1}$ for PE-L at 20 and $50 \mathrm{MPa}$ cohesive stresses.

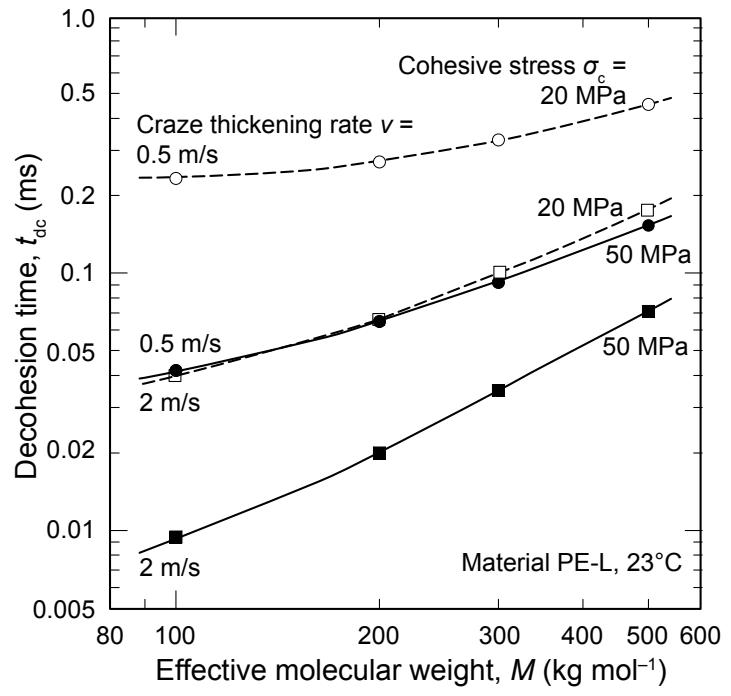

Fig. 12. Computed decohesion time as a function of effective molecular weight for typical constant thickening rates of 0.5 and $2 \mathrm{~m} / \mathrm{s}$ for PE-L at 20 and $50 \mathrm{MPa}$ cohesive stresses.

Figure 11 plots decohesion time as a function of constant craze thickening rate on the basis of this effective molecular weight $M_{\text {eff }}$, whose effect 

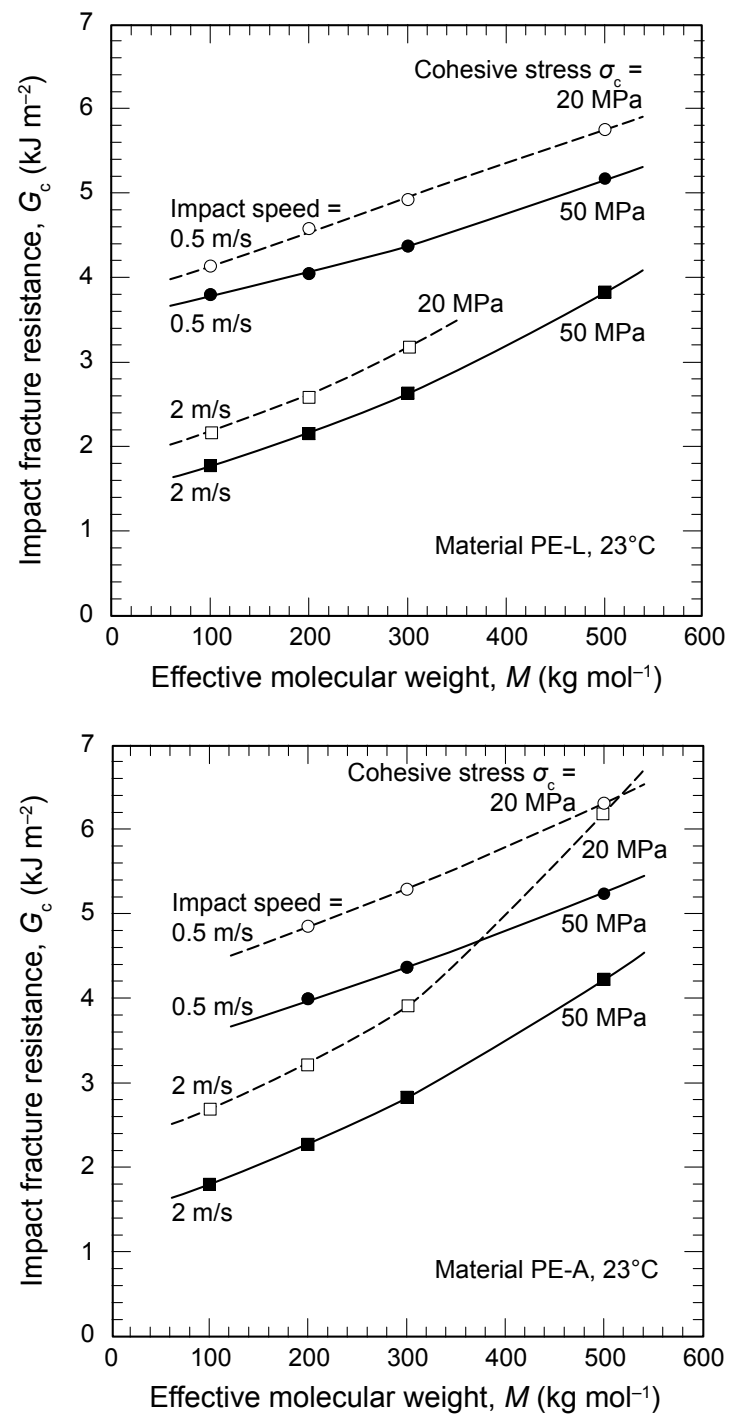

Fig. 13. Computed impact fracture resistance for (a) PE-L and (b) PE-A, as a function of effective molecular weight, at 20 and $50 \mathrm{MPa}$ cohesive stresses and at 0.5 and $2 \mathrm{~m} / \mathrm{s}$ impact speeds.

becomes significant only at high speeds. Figure 12 shows that for two constant thickening speeds and for a wider range of molecular weight within what might be thought of as representative values for PE - the decohesion time, and hence surface energy, increases substantially with increasing molecular weight. Figure 13 shows that the predicted impact fracture resistance $G_{\mathrm{c}}$ to impact fracture also increases, but much more modestly; this is one sign that the two test methods will not necessarily provide equivalent information on structure/property trends. 

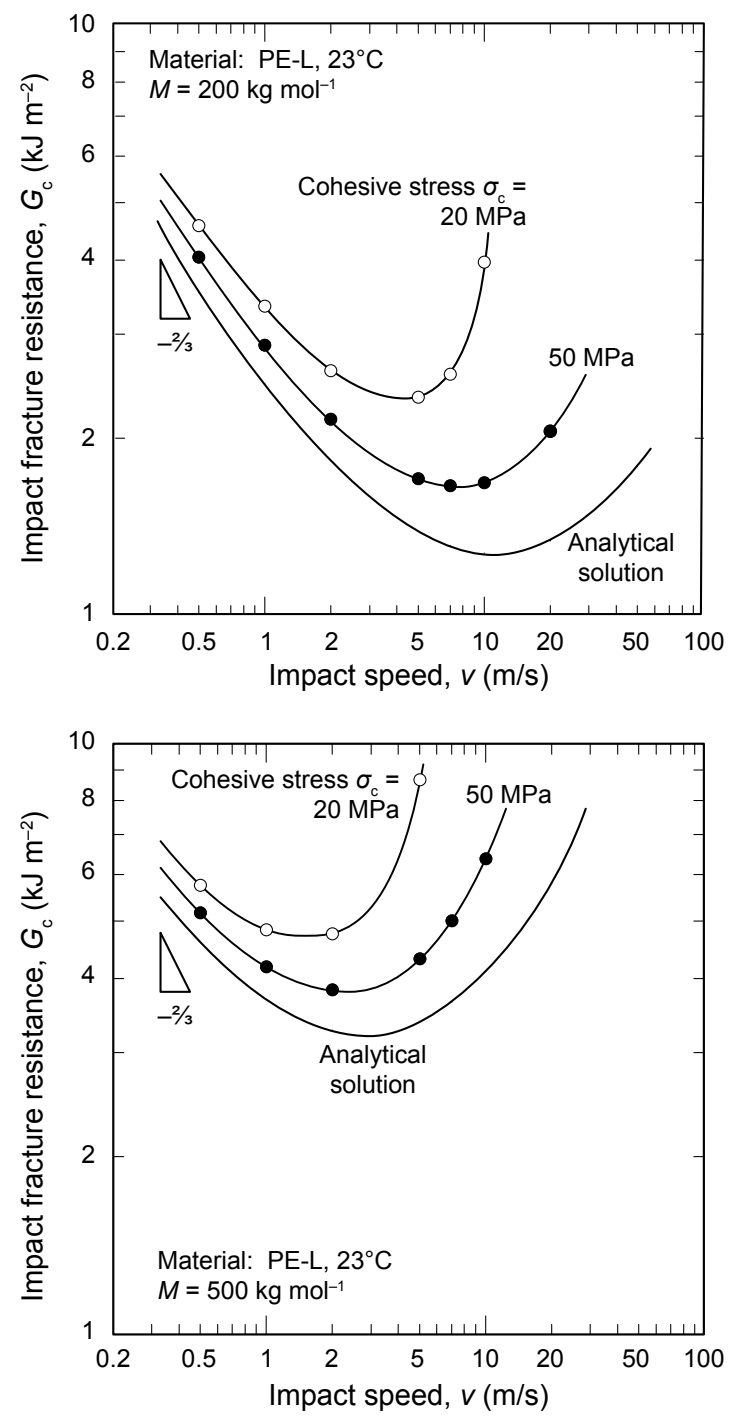

Fig. 14. Computed impact fracture resistance vs. impact speed for model material PE-L of two effective molecular weights of (a) 200 and (b) $500 \mathrm{~kg} \mathrm{~mol}^{-1}$, at 20 and $50 \mathrm{MPa}$ cohesive stresses.

\subsection{Effect of impact speed}

Figures 14 and 15 present, for PE-L and PE-A, the dependence of $G_{\mathrm{C}}$ on impact speed for two cohesive stress values and two $M_{\text {eff }}$ values. The computed $G_{\mathrm{C}}$ has a minimum at roughly the same impact speed as the analytical $G_{\mathrm{C}}$ value does; as mentioned for Fig. 6b, the analytical results are independent of cohesive stress. As impact speed is reduced below this speed, $G_{\mathrm{c}}$ tends to the signature $-2 / 3$ power rate dependence. Again, the results of PE-B are very similar to those of PE-A and are not shown here. 

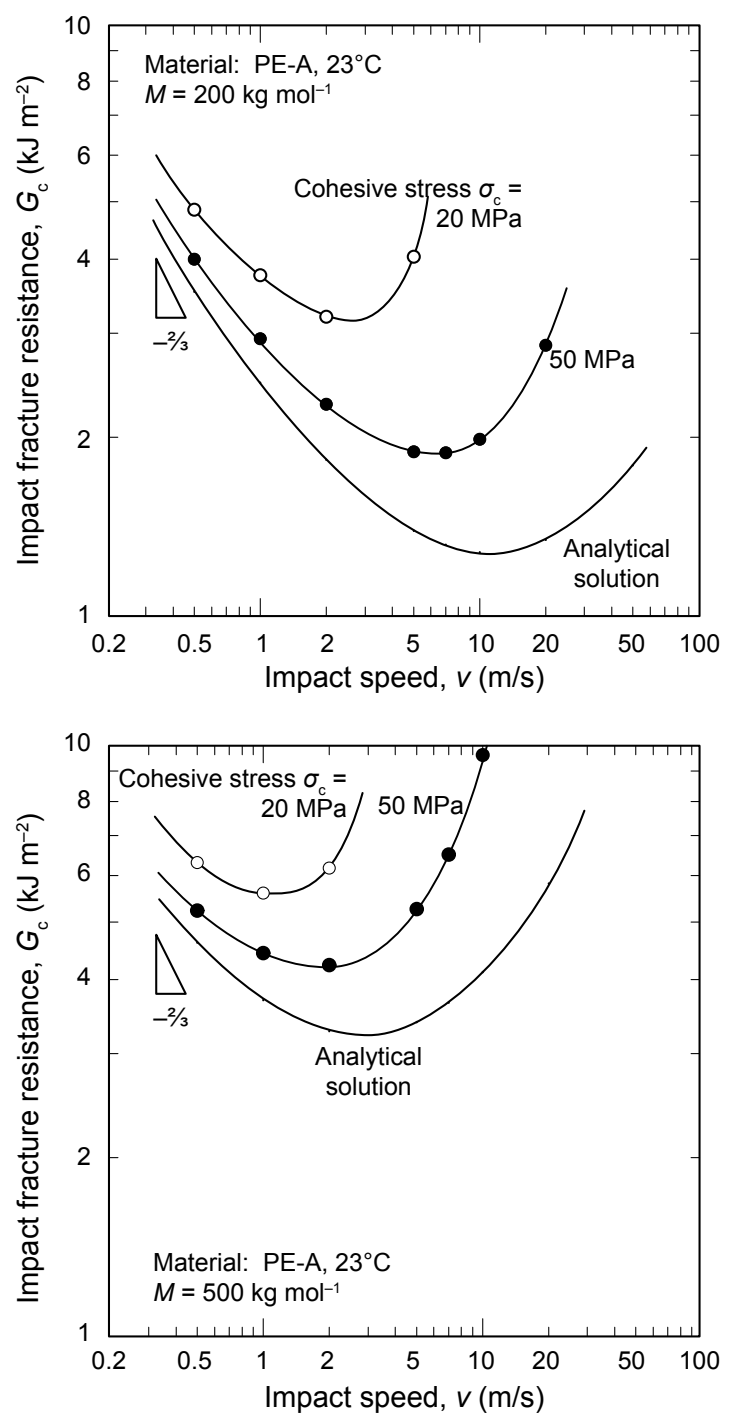

Fig. 15. Computed impact fracture resistance vs. impact speed for model material PE-A of two effective molecular weights of (a) 200 and (b) $500 \mathrm{~kg} \mathrm{~mol}^{-1}$, at 20 and $50 \mathrm{MPa}$ cohesive stresses.

\section{Discussion}

\subsection{Micromechanistic aspects}

By improving the modelling, it has been shown that adiabatic decohesion is not feasible for the small craze extension ratios which characterise bulk 'cold' drawing, as we had previously suggested (Leevers et al. (2000)). Meanwhile, Plummer (1994) has questioned the feasibility of the extension ratios calculated in $\S 5.3$. He points out that using the extended chain length as a structural parameter implies that every chain is fully end-toend extensible, which cannot be true if a stable network of entanglements 
is 'frozen in' by crystallisation. If $M_{\text {eff }}$ is identified as the entanglement molecular weight (about $2 \mathrm{~kg} \mathrm{~mol}^{-1}$ for PE) Eqn. (24) gives a maximum extension of about 4.5 and an extended chain length between entanglements, from Eqn. (23), of about $18 \mathrm{~nm}$ - one hundredth of that for the extended chain.

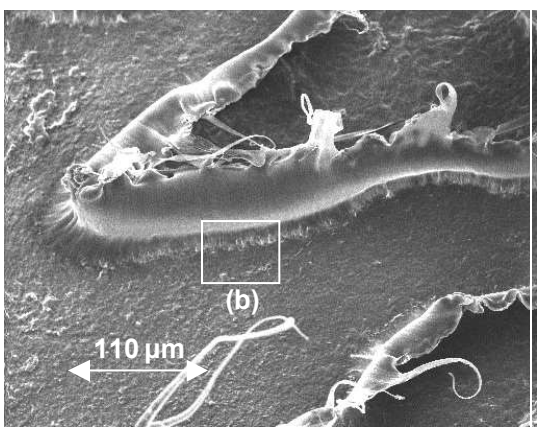

(a)

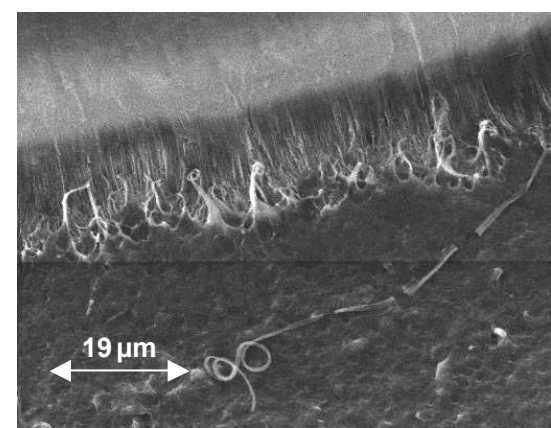

(b)

Fig. 16. Fibrillar structure seen beneath a fast-fracture surface flake (Hazra (2000))

However, the 'natural' draw ratio can be regarded less as a chain extension parameter than as a continuum parameter determined by the true stress versus true strain characteristic - specifically, by the ratio of yield stress to strain hardening modulus (Haward (1995)). The latter may indeed be a network parameter, but the entanglement density inferred from hardening data tends to decrease with increasing temperature (Hillmansen et al. (2000)). Even at low temperatures and isothermal conditions 4.5 is not an untypical value of $\lambda_{\mathrm{D}}$ : many PEs can be drawn to higher ratios. In the gel-like state which would prevail in a highly drawn polymer approaching fusion, much larger extensions will be possible.

Nevertheless, a more sophisticated model should recognise that adiabatic fibril extension takes place in two phases - 'cold' before, and 'hot' after active layer fusion (see Fig. 2) - and that the extensibilities and cohesive stresses for these phases will differ. For PE, evidence for the latter has been inferred from craze size measurements (Leevers (2000)). Direct evidence of adiabatic craze density is not accessible. Because decohesion takes place at the craze/bulk interface, the craze (which will anyway then spring back to a higher density) is hidden under a 'flake' of solidified active layer on one or other surfaces, although the edge view of Fig. 16 has found it. 


\subsection{Impact resistance and $R C P$ resistance}

A key objective of this study, as identified in the Introduction, was to relate impact fracture resistance $G_{\mathrm{C}}$ to dynamic fracture resistance $G_{\mathrm{D}}$ for tough polymers. This relationship is important to those who must develop, using small specimens, polymers which will resist large-scale steady state dynamic fracture, e.g. rapid crack propagation in pressurised plastic pipelines. Although specific test methods for the measurement of RCP resistance have been developed (e.g. Wheel and Leevers (1993b), Greenshields and Leevers (1996)), none has gained widespread use. Both 'constant thickening rate' and 'impact fracture' tests can be made on small specimens, but the present results suggest that they will not provide the same data. Which of them better represents RCP properties?

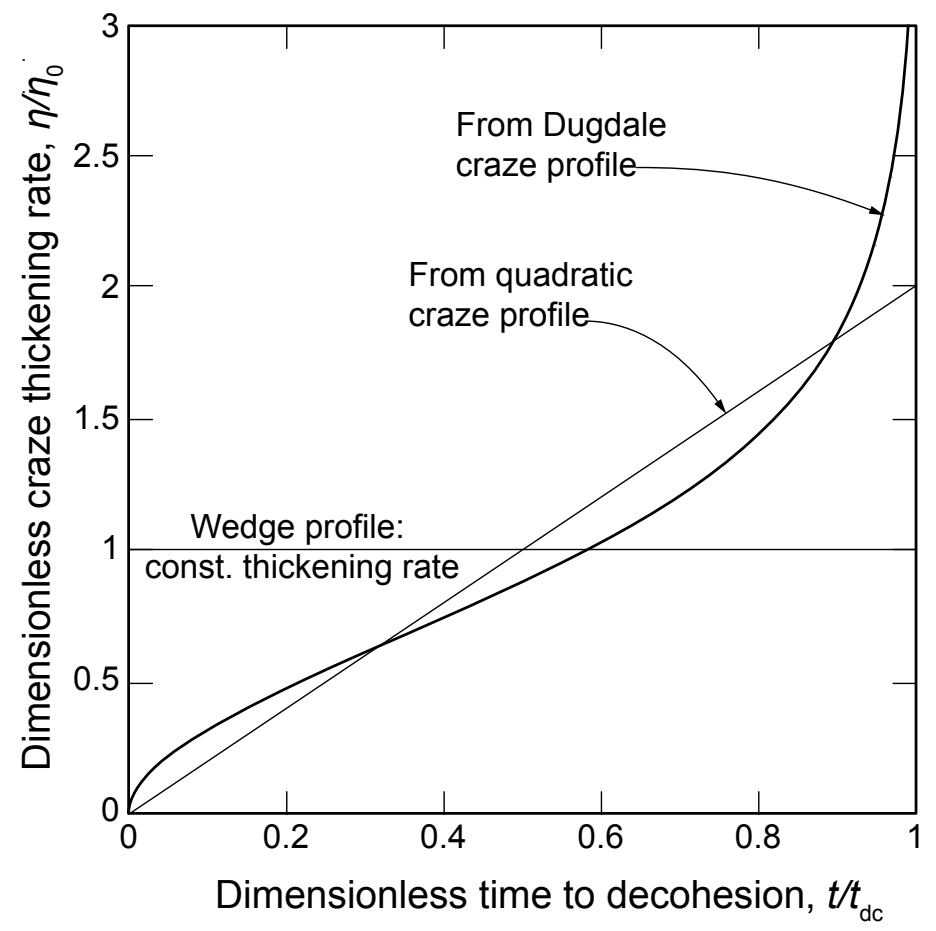

Fig. 17. Profile of cohesive surface opening speed at a point traversed by a Dugdale-Barenblatt zone.

As the cusp-shaped craze profile of Fig. 1 sweeps past a fixed material point at constant speed $\dot{a}$, it imposes the craze thickening rate history shown in Fig. 17. The rate of craze thickening is neither the constant

$$
\dot{\eta}_{0}=\frac{8}{\pi} \frac{\sigma_{\mathrm{c}}}{E^{\prime}} \dot{a}
$$

assumed by Leevers (1995), nor does it linearly increase as in an impact 
fracture test; however the latter, at a rate

$$
\dot{\eta} \approx 2 \frac{\xi}{c} \dot{\eta}_{0}=2 \frac{\dot{\eta_{0}}}{c} t
$$

is clearly a better approximation. An exact analytical solution for the DugdaleBarenblatt craze profile can be obtained and the numerical method introduced here can also (with more difficulty) be applied, but these results will be deferred to a later publication. The impact fracture approximation leads to a useful translation between impact and RCP results: impact fracture tests - even at the high speeds necessary - are simpler than RCP tests, and more work has been put into refining experimental methods for them (ISO 17281; Rager (2003))

Substituting in Eqn. (25) for the Dugdale zone length $c$ and differentiating w.r.t. time gives

$$
\ddot{\eta} \approx 2\left(\frac{8}{\pi} \frac{\sigma_{\mathrm{c}}}{E^{\prime}}\right)^{2} \frac{\sigma_{\mathrm{c}}}{G_{\mathrm{D}}} \dot{a}^{2}
$$

which can be directly compared to Eqn. (13) for the unmoving impactloaded crack tip at $\eta=\xi$. Thus a fixed point in the material near the tip of a crack loaded in impact will experience a similar thermal history as a fixed point in the same material passed by a craze driven at an equivalent crack velocity $\dot{a}_{\mathrm{eq}}$, where

$$
2\left(\frac{8}{\pi} \frac{\sigma_{\mathrm{c}}}{E^{\prime}}\right)^{2} \frac{\sigma_{\mathrm{c}}}{G_{\mathrm{D}}\left(\dot{a}_{\mathrm{eq}}\right)} \dot{a}_{\mathrm{eq}}^{2} \approx \frac{E^{\prime}}{\sigma_{\mathrm{c}}} \Gamma_{\mathrm{v}}\left(\frac{a}{W}\right) \frac{1}{W} \dot{v}^{2}
$$

Since (according to the present theory) both points will then suffer decohesion at the same time, we can write $G_{\mathrm{D}}\left(\dot{a}_{\mathrm{eq}}\right)=G_{\mathrm{c}}(\dot{v})$ and simplify $(27)$ to

$$
\dot{a}_{\mathrm{eq}}=\frac{\pi}{8}\left(\frac{E^{\prime}}{\sigma_{\mathrm{c}}}\right)^{2}\left\{\Gamma_{\mathrm{v}}\left(\frac{a}{W}\right) \frac{G_{\mathrm{c}}(\dot{v})}{2 W E^{\prime}}\right\}^{1 / 2} \dot{v}
$$

in which all of the geometrical parameters refer to the impact configuration.

Equation (28) draws out a direct equivalence between resistance $G_{\mathrm{C}}(\dot{v})$ to fracture initiation under impact at a speed $\dot{v}$, and resistance $G_{\mathrm{D}}(\dot{a})$ to rapid crack propagation at a crack speed $\dot{a}$. Two points are important here. Firstly, as noted by Kanninen and Popelar (1985), constant-speed crack propagation on the falling (i.e. low speed) sector of $G_{\mathrm{D}}(\dot{a})$ is usually precluded by stability considerations: if $G_{\mathrm{D}}(\dot{a})$ decreases more rapidly than the driving force $G$ with increasing speed, any deceleration will result in arrest. Thus only data at and to the right of the $G_{\mathrm{C}}(\dot{v})$ minimum is of interest. Secondly, the minimum $G_{\mathrm{C}}$ itself - which is, according to this model, identical to the minimum $G_{\mathrm{D}}$ - is likely to be of greatest interest, and this minimum is often only accessible at relatively high impact speeds such as those achieved at nearly $10 \mathrm{~m} / \mathrm{s}$ by Horsfall et al. (2003). 


\section{Conclusions}

A one-dimensional finite volume model of work, heat and mass transfer through the active layer of a Lauterwasser-Kramer craze has been demonstrated for the cases of constant and linearly increasing thickening rate in linear and non-linear polymers. The results confirm that adiabatic decohesion is viable for realistic values of thickening rate, cohesive stress and craze density. The numerical formulation generally confirms the predictions of the analytical one for non dense crazes, but offers many more possibilities for exploring potential mechanisms of impact decohesion in both crystalline and amorphous polymers. Changes in enthalpy with temperature corresponding to first-order transitions do not greatly change the predictions of the model: ultimately, it is the 'heat to melt' which determines fracture resistance. Increasing molecular weight - which decreases craze density but increases the structural dimension - gives a net increase in impact fracture resistance. Finally the model predicts that the fracture resistance passes through a minimum as the impact speed increases, and suggests that this minimum value is approximately equal to the minimum dynamic fracture resistance.

\section{Acknowledgements}

This work was funded by the Engineering and Physical Sciences Research Council. Much of it was completed while one author (PSL) visited Leoben University on sabbatical leave, and the author would like to express his gratitude to Prof. Reinhold W. Lang, and to Zoltan Major and others in his group, for their support.

\section{A Appendix}

As described in $\S 3$, the heat exchanges defined in Eqns. (1), (5) and (7) vary with position $j-j_{\mathrm{a}}$ (Fig. 5), where $j_{\mathrm{a}}$ is the active element: $j<j_{\mathrm{a}}$ in the fibril, $j=j_{\mathrm{a}}$ in the one-cell thick active layer and $j>j_{\mathrm{a}}$ in the bulk material. The total heat flow into each plane of elements is

$$
\begin{aligned}
q= & -\frac{2}{\left(L_{\mathrm{j}-1}+L_{\mathrm{j}}\right)}\left[k\left(T_{\mathrm{j}}\right) A_{\mathrm{j}} T_{\mathrm{j}}-k\left(T_{\mathrm{j}-1}\right) A_{\mathrm{j}-1} T_{\mathrm{j}-1}\right] \\
& +\frac{2}{\left(L_{\mathrm{j}}+L_{\mathrm{j}+1}\right)}\left[k\left(T_{\mathrm{j}+1}\right) A_{\mathrm{j}+1} T_{\mathrm{j}+1}-k\left(T_{\mathrm{j}}\right) A_{\mathrm{j}} T_{\mathrm{j}}\right]
\end{aligned}
$$




$$
\begin{gathered}
+\beta\left(\sigma_{\mathrm{c}}(\eta)_{\mathrm{j}}-\frac{\left.N_{\mathrm{j}-1} \Delta H_{f} \dot{(\eta}\right)_{\mathrm{j}}}{\lambda_{f}}\right) \quad\left(\text { if } j=j_{\mathrm{a}}\right) \\
+4 h L_{0}\left(\lambda_{\mathrm{F}} N\right)^{1 / 2}\left(T_{\mathrm{j}}-T_{0}\right) \quad\left(\text { if } j<j_{\mathrm{a}}\right)
\end{gathered}
$$

Since $L_{\mathrm{j}}=\lambda_{\mathrm{j}} L_{0}$ and $A_{\mathrm{j}}=\frac{1}{\lambda_{\mathrm{j}}}$ (where $L_{\mathrm{j}}, A_{\mathrm{j}}$ and $\lambda_{\mathrm{j}}$ are the length, crosssectional area and axial stretch of element $j$ ) $q$ reduces to

$$
q=\frac{1}{L_{0}}\left[X_{\mathrm{j}-1} k\left(T_{\mathrm{j}-1}\right) T_{\mathrm{j}-1}+X_{\mathrm{j}} k\left(T_{\mathrm{j}}\right) T_{\mathrm{j}}+X_{\mathrm{j}+1} k\left(T_{\mathrm{j}+1}\right) T_{\mathrm{j}+1}\right]+\cdots
$$

where

$$
\begin{gathered}
X_{\mathrm{j}-1}=\frac{2}{\lambda_{\mathrm{j}-1}\left(\lambda_{\mathrm{j}-1}+\lambda_{\mathrm{j}}\right)} \\
X_{\mathrm{j}}=-2\left[\frac{1}{\lambda_{\mathrm{j}-1}\left(\lambda_{\mathrm{j}-1}+\lambda_{\mathrm{j}}\right)}+\frac{1}{\lambda_{\mathrm{j}+1}\left(\lambda_{\mathrm{j}+1}+\lambda_{\mathrm{j}}\right)}\right]
\end{gathered}
$$

and

$$
X_{\mathrm{j}+1}=\frac{2}{\lambda_{\mathrm{j}+1}\left(\lambda_{\mathrm{j}}+\lambda_{\mathrm{j}+1}\right)}
$$

Table A.1 shows the values of these constants in terms of $j-j_{\mathrm{a}}$.

Table A.1

Finite volume weights for the two-sector domain

$$
\left(j_{a}-j\right)>1 \quad\left(j_{a}-j\right)=1 \quad j=j_{a} \quad j>j_{a}
$$

(in fibril) (on cohesive surface) (in active layer) (in bulk material)

\begin{tabular}{lcccc}
\hline$X_{\mathrm{j}-1}$ & $\frac{1}{\lambda_{\mathrm{F}}^{2}}$ & $\frac{1}{\lambda_{\mathrm{F}}^{2}}$ & $\frac{2}{\lambda_{\mathrm{F}}\left(\lambda_{\mathrm{F}}+1\right)}$ & 1 \\
$X_{\mathrm{j}}$ & $-\frac{2}{\lambda_{\mathrm{F}}^{2}}$ & $-\frac{1}{\lambda_{\mathrm{F}}^{2}} \frac{\left(3 \lambda_{\mathrm{F}}+1\right)}{\left(\lambda_{\mathrm{F}}+1\right)}$ & $-\frac{3+\lambda_{\mathrm{F}}}{1+\lambda_{\mathrm{F}}}$ & -2 \\
$X_{\mathrm{j}+1}$ & $\frac{1}{\lambda_{\mathrm{F}}^{2}}$ & $\frac{2}{\left(1+\lambda_{\mathrm{F}}\right)}$ & 1 & 1 \\
\hline
\end{tabular}

\section{References}

Bjerke, T., Lambros, J., 2003. Theoretical development and experimental validation of a thermally dissipative cohesive zone model for dynamic fracture of amorphous polymers. Journal of the Mechanics and Physics of Solids 51, 1147-1170.

Bjerke, T., Li, Z., Lambros, J., 2002. Role of plasticity in heat generation during high rate deformation and fracture of polycarbonate. International Journal of Plasticity 18, 549-567.

Bougaut, O., Rittel, D., 2001. On crack-tip cooling during dynamic crack initiation. International Journal of Solids and Structures 38, 2517-2532. 
Brough, I., Haward, R., Healey, G., Wood, A., 2004. Scanning electron micrographs of high density polyethylene fracture surfaces. Polymer 45, 3115-3123.

Carslaw, H., Jaeger, J., 1959. Conduction of heat in solids. Oxford University Press, Oxford, UK.

Chan, M., Williams, J., 1983. Slow stable crack growth in high density polyethylenes. Polymer 24, 234-244.

Channell, A., Clutton, E., 1996. Role of crazing in impact fracture toughness of polyethylene pipe grades. Plastics, Rubber and Composites 25 (6), 272.

Chen, H., Karger-Kocsis, J., Wu, J., Varga, J., 2002. Fracture toughness of $\alpha$ - and $\beta$-phase polypropylene homopolymers and random- and blockcopolymers. Polymer 43, 6505-6514.

Clutton, E., Channell, A., 1995. Energy partitioning in impact fracture toughness measurements. In: Impact and Dynamic Fracture of Polymers and Composites. Mechanical Engineering Publications, Bury St. Edmunds, UK, pp. 215-224.

Döll, W., 1976. International Journal of Fracture 12, 595-605.

Engelter, A., Müller, F., 1958. Thermal effects of mechanical deformation, especially of high polymers (in German). Kolloid Zeitschrift 157, 89.

Fuller, K., Fox, P., Field, J., 1975. The temperature rise at the tip of fastmoving cracks in glassy polymers. Proceedings of the Royal Society, Series A 341, 537-557.

Gensler, R., Plummer, C., Grein, C., Kausch, H., 2000. Influence of the loading rate on the fracture resistance of isotactic polypropylene and impact modified isotactic polypropylene. Polymer 41, 3809-3819.

Godovsky, Y., 1992. Thermophysical properties of polymers. ISBN 3-54054160-8. Springer-Verlag, Berlin.

Greenshields, C., Leevers, P., 1996. Rapid crack propagation in plastic water pipes: measurement of dynamic fracture resistance. International Journal of Fracture 79, 85-95.

Haward, R., 1994. Heating effects in the deformation of thermoplastics. Thermochimica Acta 247, 87-109.

Haward, R., 1995. The application of a Gauss-Eyring model to predict the behaviour of thermoplastics in tensile experiments. Journal of Polymer Science: Part B: Polymer Physics 33, 1481-1494.

Hazra, S. K., 2000. Crazing and yielding of polyethylene under impact. Ph.D. thesis, University of London.

Hillmansen, S., Hobeika, S., Haward, R., Leevers, P., 2000. The effect of strain rate and temperature on the tensile deformation of pipe-grade polyethylene. In: Proc. 11th Int. Conf. Deformation, Yield and fracture of polymers. IOM Communications, London, Cambridge, UK, pp. 273276.

Horsfall, I., Watson, C., Cilese, C., 2003. A drop tower method for high rate fracture toughness testing of polymers. In: Blackman, B., Pavan, A., 
Williams, J. (Eds.), Fracture of Polymers, Composites and Adhesives II. Elsevier Ltd. and ESIS, pp. 221-229.

Kanninen, M., Popelar, C., 1985. Advanced Fracture Mechanics. Oxford University Press, Oxford UK.

Lauterwasser, B., Kramer, E., 1979. Microscopic mechanisms and mechanics of craze growth and fracture. Philosophical Magazine A39, 469.

Leevers, P., 1995. Impact and dynamic fracture of tough polymers by thermal decohesion in a Dugdale zone. International Journal of Fracture 73 (2), 109-127.

Leevers, P., 1996. Impact and dynamic fracture resistance of crystalline thermoplastics: prediction from bulk properties. Polymer Engineering and Science 36 (18), 2296-2305.

Leevers, P., Haward, R., Hazra, S., Hillmansen, S., 2000. Fast fracture of thermoplastics as a micro-scale tensile drawing process. In: Williams, J., Pavan, A. (Eds.), Fracture of Polymers, Composites and Adhesives, ESIS Publication 27. Elsevier, pp. 335-345.

Leevers, P., Hazra, S., Wang, L., 2003. Cohesive properties of a crystalline polymer craze under impact extension. In: Blackman, B., Pavan, A., Williams, J. (Eds.), Fracture of Polymers, Composites and Adhesives II. ISBN 0-08-044195-5. Elsevier Science, p. 578.

Leevers, P., Morgan, R., 1995. Impact fracture of polyethylene: a nonlinear-elastic thermal decohesion model. Engineering Fracture Mechanics 52 (6), 999-1014.

Leevers, P. S., 2000. Interpreting instrumented three-point bend fracture tests on craze-forming polymers. Plastics, Rubber and Composites Processing and Applications 29 (9), 453-459.

O'Connell, P., Duckett, R., Ward, I., 2002. Brittle-ductile transitions in polyethylene. Polymer Engineering and Science 42 (7), 1493-1508.

Pandya, K., Williams, J., 2000. Measurement of cohesive zone parameters in tough polyethylene. Polymer Engineering and Science 40 (8), 17651776.

Pegoretti, A., Pandini, S., Ricco, T., 2004. Post-yield compressed semicrystalline poly(butylene terephthalate): energy storage and release. Polymer 45, 3497-3504.

Plummer, C., 1994. Personal communication.

Rager, A., 2003. Analysis of high-rate fracture tests on polymers. Ph.D. thesis, University of London.

Rittel, D., 1999. On the conversion of plastic work to heat during high strain rate deformation of glassy polymers. Mechanics of Materials 31, 131-139.

Smith, K., Wang, J., 1999. The breaking strength of imperfect (real) polymer fibres. Polymer 40, 7251-7260.

Steenbrink, A., Janik, H., Gaymans, R., 1997. Deformation and fracture of styrene-acrylonitril copolymer - rubber blends: Microscopy studies of deformation zones. Journal of Materials Science 32 (20), 5505-5511. 
Tordjeman, P., Robert, C., Marin, G., Gerard, P., 2001. The effect of $\alpha, \beta$ crystalline structure on the mechanical properties of polypropylene. European Physical Journal E 4, 459-465.

Wheel, M., Leevers, P., 1993a. High speed double torsion tests on tough polymers. II: Nonlinear elastic dynamic analysis. International Journal of Fracture 61, 349-359.

Wheel, M. A., Leevers, P. S., 1993b. High Speed Double Torsion tests on tough polymers. II: Nonlinear elastic dynamic analysis. International Journal of Fracture 61, 349-359.

Williams, J., Hodgkinson, J., 1981. Crack blunting effects in impact tests on polymers. Proceedings of the Royal Society (London) A375, 231-248.

Yu, J., Summers, J., Hiltner, A., Baer, E., 2004. Quasi-brittle to ductile transition in impact-modified PVC. Journal of Vinyl and Additive Technology 10 (1), 11-16. 